\title{
Conditional Deletion of CC2D1A Reduces Hippocampal Synaptic Plasticity and Impairs Cognitive Function through Rac1 Hyperactivation
}

\author{
Cheng-Yi Yang, ${ }^{1}$ Ting-Hsuan Yu, ${ }^{1}$ Wan-Ling Wen, ${ }^{2}$ Pin Ling, ${ }^{3}$ and $\odot$ Kuei-Sen Hsu ${ }^{1,2}$ \\ ${ }^{1}$ Institute of Basic Medical Sciences, ${ }^{2}$ Department of Pharmacology, and ${ }^{3}$ Department of Microbiology \& Immunology, College of Medicine, National Cheng \\ Kung University, Tainan 70101, Taiwan
}

Coiled-coil and C2 domain containing $1 \mathrm{~A}(\mathrm{CC} 2 \mathrm{D} 1 \mathrm{~A})$ is an evolutionarily conserved protein, originally identified as a nuclear factor- $\kappa \mathrm{B}$ activator through a large-scale screen of human genes. Mutations in the human $C c 2 d 1 a$ gene result in autosomal recessive nonsyndromic intellectual disability. It remains unclear, however, how $C c 2 d 1 a$ mutation leads to alterations in brain function. Here, we have taken advantage of Cre/loxP recombinase-based strategy to conditionally delete $C c 2 d 1 a$ exclusively from excitatory neurons of male mouse forebrain to examine its role in hippocampal synaptic plasticity and cognitive function. We confirmed the expression of CC2D1A protein and mRNA in the mouse hippocampus. Double immunofluorescence staining showed that CC2D1A is expressed in both excitatory and inhibitory neurons of the adult hippocampus. Conditional deletion of $C c 2 d 1 a(\mathrm{cKO})$ from excitatory neurons leads to impaired performance in object location memory test and altered anxiety-like behavior. Consistently, cKO mice displayed a deficit in the maintenance of LTP in the CA1 region of hippocampal slices. Cc2dla deletion also resulted in decreased complexity of apical and basal dendritic arbors ofCA1 pyramidal neurons. An enhanced basal Rac1 activity was observed following $C c 2 d 1 a$ deletion, and this enhancement was mediated by reduced SUMO-specific protease 1 (SENP1) and SENP3 expression, thus increasing the amount of Rac1 SUMOylation. Furthermore, partial blockade of Racl activity rescued impairments in LTP and object location memory performance in cKO mice. Together, our results implicate Rac1 hyperactivity in synaptic plasticity and cognitive deficits observed in Cc2d1a cKO mice and reveal a novel role for CC2D1A in regulating hippocampal synaptic function.

Key words: CC2D1A; cognition; hippocampus; LTP; Rac1; SENP

Significance Statement

CC2D1A is abundantly expressed in the brain, but there is little known about its physiological function. Taking advantage of Cc2d1a cK0 mice, the present study highlights the importance of CC2D1A in the maintenance of LTP at Schaffer collateral-CA1 synapses and the formation of hippocampus-dependent long-term object location memory. Our findings establish a critical link between elevated Racl activity, structural and synaptic plasticity alterations, and cognitive impairment caused by $C c 2 d 1 a$ deletion. Moreover, partial blockade of Racl activity rescues synaptic plasticity and memory deficits in Cc2d1 a cKO mice. Such insights may have implications for the utility of Racl inhibitors in the treatment of intellectual disability caused by $C c 2 d 1 a$ mutations in human patients.

\section{Introduction}

Coiled-coil and C2 domain containing 1A (CC2D1A) is the first member of the $C c 2 d 1$ gene family that contains a protein kinase $\mathrm{C}$

\footnotetext{
Received Sept. 17, 2018; revised April 11, 2019; accepted April 14, 2019.

Author contributions: C.-Y.Y., T.-H.Y., W.-L.W., P.L., and K.-S.H. designed research; C.-Y.Y., T.-H.Y., and W.-L.W. performed research; C.-Y.Y., T.-H.Y., and W.-L.W. analyzed data; C.-Y.Y. and K.-S.H. wrote the first draft of the paper; C.-Y.Y., P.L., and K.-S.H. edited the paper; C.-Y.Y., P.L., and K.-S.H. wrote the paper; P.L. contributed unpublished reagents/analytic tools.

This work was supported by National Health Research Institute Grant NHRI-EX107-10613NI and Ministry of Science and Technology Grant 106-2320-B-006-026-MY3; 107-2320-B-006-037-MY3 (Taiwan).

The authors declare no competing financial interests.
}

conserved region 2 (C2) domain, four Drosophila melanogaster 14 (DM14) domains and a predicted helix-loop-helix DNA binding domain (Ou et al., 2003). It was first identified in a large-scale screen for characterization of the human genes that activate the nuclear factor $-\kappa \mathrm{B}(\mathrm{NF}-\kappa \mathrm{B})$ signaling in HEK293 cells (Matsuda et al., 2003; Shi et al., 2012). Later work has confirmed that CC2D1A activates NF- $\kappa \mathrm{B}$ through the canonical $\mathrm{I} \kappa \mathrm{B}$ kinase path-

Correspondence should be addressed to Kuei-Sen Hsu at richard@mail.ncku.edu.tw. https://doi.org/10.1523/JNEUROSCI.2395-18.2019

Copyright $\odot 2019$ the authors 
way (Zhao et al., 2010). In addition to acting as a NF- $\kappa$ B activator, there is increasing evidence that CC2D1A regulates multiple cellular signaling pathways. For example, it can act as a transcriptional repressor of the serotonin $1 \mathrm{~A}\left(5-\mathrm{HT}_{1 \mathrm{~A}}\right)$ receptor and dopamine $\mathrm{D}_{2}$ receptor genes and is called Freud-1 (FRE under Dual repression binding protein 1) (Ou et al., 2003; Rogaeva et al., 2007; Szewczyk et al., 2010). CC2D1A also functions as a scaffold-like protein to activate 3-phosphoinositide-dependent protein kinase 1/Akt pathway in epidermal growth factor signaling and is named Aki-1 (Akt kinase-interacting protein-1) (Nakamura et al., 2008). It is also a positive regulator of the cAMP/ cAMP-dependent protein kinase A pathway through fine-tuning the negative feedback loop that acts via protein kinase A activation of phosphodiesterase 4D (Al-Tawashi et al., 2012; AlTawashi and Gehring, 2013). In the innate immune system, CC2D1A (also named TBK1-associated protein in endolysosomes) can modulate the Toll-like receptor and retinoic acidinducible gene I-like receptor signaling pathways that induce the production of inflammatory cytokines, including interferon- $\beta$ (Chang et al., 2011; Chen et al., 2012). Moreover, evidence suggests that CC2D1A can interact with cohesin in centrosomes, and this interaction is important for preventing premature cleavage in centriole cohesion in HeLa cells (Nakamura et al., 2009). While the molecular features of CC2D1A have been elucidated over the past few years, most functional studies of this protein were performed using the cell culture systems. The functional relevance of CC2D1A in vivo, however, has only just begun to be characterized.

By using ISH analysis, Cc2d1 a mRNA is found throughout the mouse brain but is particularly abundant in the cerebral cortex, hippocampus, basal ganglia, and hypothalamus (Basel-Vanagaite et al., 2006; Zhao et al., 2011). Importantly, mutations in the human $C c 2 d 1 a$ gene result in autosomal recessive nonsyndromic intellectual disability, autism spectrum disorder, and seizures (Basel-Vanagaite et al., 2006; Manzini et al., 2014; Sener et al., 2016). In addition, using association testing and linkage analysis, Freischmidt et al. (2015) further demonstrated that haploinsufficiency of TBK1, a CC2D1A-interacting protein, or loss of interaction of the C-terminal TBK1 coiled-coil domain with its adaptor proteins can cause familial amyotrophic lateral sclerosis and frontotemporal dementia. In parallel, a recent study has reported that $C c 2 d 1 a$ loss of function causes abnormal neuronal morphology in the mouse somatosensory cortex and robust behavioral phenotypes included learning and memory impairments, social deficits, hyperactivity, anxiety, and obsessive grooming (Oaks et al., 2017). However, cellular and molecular mechanisms by which CC2D1A regulates these neuropsychiatricrelated behaviors have yet to be elucidated. In this study, we applied the Cre/loxP recombinase-based strategy to conditionally delete $C c 2 d 1 a$ exclusively in excitatory neurons of the mouse forebrain to examine its role in hippocampal synaptic plasticity and cognitive function. We demonstrated that $C c 2 d 1 a$ deletion from excitatory neurons leads to impaired performance in object location memory (OLM) test and a deficit in the maintenance of hippocampal CA1 LTP. We also identified Rac1 interplay as a key player in the observed synaptic plasticity dysfunction and memory impairment in the Cc2d1a conditional KO (cKO) mice. Remarkably, these deficits were effectively rescued upon partial Racl blockade.

\section{Materials and Methods}

Animals. All experimental procedures were approved by the Institutional Animal Care and Use Committee of National Cheng Kung University, in accordance with the National Institutes of Health Guide for the care and use of laboratory animals. Mice were housed in groups of 3 on a $12 \mathrm{~h}$ light/dark cycle in a humidity- and temperature-controlled $\left(25 \pm 1^{\circ} \mathrm{C}\right)$ rooms with ad libitum access to food and drinking water and behavioral testing occurred during the light cycle. For consistency purpose, only male mice were used in all experiments. Floxed $C c 2 d 1 a\left(C c 2 d 1 a^{\mathrm{f} / \mathrm{f}}\right)$ mice were generated by standard techniques using a targeting containing a neomycin resistance (Neo) selection cassette flanked by FRT sites. Cc2dla gene targeting ES clone [B6J, Design ID: 49663 (72_A06)] was obtained from the Knockout Mouse Project Repository at University of California at Davis. The cKO vector that targets exon 12-14 of mouse Cc2d1a gene was constructed by cloning a 5' (5071 bp) and 3' (4772 bp) homology fragment into the PG00072_W_2_A06 vector using the recombineering techniques. Exon $12-14$ of the $C c 2 d 1 a$ gene was inserted into two flanking loxP sites. For selection purpose, the LacZ reporter and Neo flanked by two FRT loci were cloned into the upstream site of exon 12-14. Another loxP site was placed into the cassette to separate LacZ and Neo. Cc2d1a cKO mice were generated by crossing calcium/calmodulindependent protein kinase II $\alpha$ (CaMKII $\alpha)$-Cre transgenic mice [B6; Cg-Tg (Camk2 $\alpha$-Cre) T29-1Stl/J; The Jackson Laboratory] with homozygous $C c 2 d 1 a^{\mathrm{f} / \mathrm{f}}$ mice. $C c 2 d 1 a^{\mathrm{f} / \mathrm{f}}$ mice were used as the WT littermates for comparison with homozygous cKO mice. Ten- to 12-week-old congenic cKO and $C c 2 d 1 a^{\mathrm{f} / \mathrm{f}}$ mice from F3 generation were used for experiments. Glutamate decarboxylase 67-green fluorescence protein (GAD67-GFP) knock-in mice were kindly provided by Dr. Yuchio Yanagawa (Gunma University Graduate School of Medicine) and bred within our animal facility. Genetically engineered mice were genotyped by a PCR-based method using genomic DNA isolated from tail tips as previously described (Huang et al., 2014). Mice for all experiments were maintained on the C57BL/ 6 background. Mice were randomized before the behavioral assessment and the experimenter blinded to genotype. To avoid potential carryover effects, all animals are used only once throughout the study. Only male mice were used for experiments throughout the study.

Construction and production of adeno-associated virus (AAV). AAV plasmids encoding a GFP/Cre recombinase (Cre-GFP) fusion protein (Addgene, plasmid \#20781) or a GFP (AAV-GFP, plasmid \#49055) were obtained from Addgene. Plasmid DNA was amplified, purified, and collected using a standard plasmid maxiprep kit (QIAGEN). The purified plasmids were mixed into calcium chloride solution with the DNA plasmid coding AAV capsid DJ serotype and cotransfected into HEK293T cells using calcium phosphate precipitation method as previously described (Yang et al., 2012). At $72 \mathrm{~h}$ after transfection, cells were harvested and the virus was purified using the AAV purification mega kit (Cell Biolabs). Viral titers were $5 \times 10^{12}$ particles $/ \mathrm{ml}$ and stored in aliquots at $-80^{\circ} \mathrm{C}$ until use.

Stereotaxic viral injection. Recombinant AAV-GFP or AAV-Cre-GFP was injected bilaterally into the dorsal hippocampal CA1 region using standard stereotaxic procedures. Under isoflurane (2\%-5\%; Attane, Dow) anesthesia, concentrated viral solution was injected into the targeted sites $(0.5 \mu \mathrm{l}$ per site at $0.25 \mu \mathrm{l} / \mathrm{min})$ by using a Hamilton syringe with a 34-gauge blunt tip needle. The injection coordinates were as follows [measured from bregma (in $\mathrm{mm}$ )]: anterioposterior -2.0 , mediolateral \pm 1.5 , and dorsoventral -1.5 according to the description by Franklin and Paxinos (2008). All injections were performed on 8-weekold mice and were followed by a 3 week viral incubation period before starting the behavioral experiments. At the end of the experiments, mice used in behavioral tests were killed by perfusion, and the correct placement of the virus injection sites was confirmed by GFP expression for each animal. Only those mice with accurate injections in both sides of the CA1 were included in the analysis.

OLM test. The OLM test was conducted in an open-field chamber on 4 successive days as previously described (Chou et al., 2014). For the first $2 \mathrm{~d}$, mice were allowed to freely explore an empty chamber $(40 \mathrm{~cm} \times 40$ $\mathrm{cm} \times 40 \mathrm{~cm}$ ) for $10 \mathrm{~min}$ each day for adaptation. The following day, mice were rehabituated to the empty chamber for $1 \mathrm{~min}$ and then returned to their home cage while two identical objects were placed in two diagonal corners of the chamber. Afterward, mice were returned to the chamber for training and allowed to explore the objects for $10 \mathrm{~min}$. The test session was performed $24 \mathrm{~h}$ after the training session. In the test session, one of 
the familiar objects was placed in a novel location and the other familiar object was placed in the same location of training. Mice were placed in the testing chamber for $10 \mathrm{~min}$, and the time spent exploring in each object was recorded using a digital video camera and scored by EthoVision XT video tracking systems (Noldus: RRID:SCR_000441). To analyze cognitive performance, the discrimination index was calculated as follows: [(time exploring the object in novel location - time exploring the object in familiar location)/(time exploring the objects in both novel and familiar locations) $\times 100 \%]$. The chamber was thoroughly cleaned with $70 \%$ ethanol after each trial to prevent bias based on olfactory cues.

Open-field (OF) test. The OF test was performed as previously described (Lin et al., 2018). Each individual mouse was placed in the center of the test chamber and allowed to freely explore for 10 min under a dimmed illumination (10 Lux). The test chamber consisted of a square ground area $(42 \mathrm{~cm} \times 42 \mathrm{~cm})$ surrounded by a $42 \mathrm{~cm}$ high wall set on a nonreflective white plastic base. The behavior of the animals was videotaped, tracked, and analyzed with the EthoVision XT video tracking systems. Behavioral measurements included time spent in the center zone and total distance traveled in the OF. The percentage of time spent in the center zone is defined as the percentage of time for the animals exploring the center $25 \%(21 \mathrm{~cm} \times 21 \mathrm{~cm})$ of the arena of the chamber.

Elevated plus maze (EPM). The EPM test was performed as previously described (Pellow et al., 1985; Lin et al., 2018). The apparatus was made from black Plexiglas with a light gray floor and consisted of two open (25 $\mathrm{cm} \times 5 \mathrm{~cm} \times 0.5 \mathrm{~cm})$ and two closed arms $(25 \mathrm{~cm} \times 5 \mathrm{~cm} \times 16 \mathrm{~cm})$, which extended from a central platform $(5 \times 5 \mathrm{~cm})$ at $50 \mathrm{~cm}$ from the ground. Each individual mouse was placed in the center area facing an open arm and allowed to freely explore the maze for $15 \mathrm{~min}$. The apparatus was illuminated with dimmed light (10 Lux). The behavior of the animals was videotaped, tracked, and analyzed with the EthoVision XT video tracking systems. Behavioral measurements included time spent and numbers of entries into the open versus closed arms.

Light-dark box (LDB) test. The LDB test was performed as previously described (Bourin and Hascoët, 2003). The apparatus consists of a square $(30 \mathrm{~cm} \times 30 \mathrm{~cm}$ ) divided into a small dark safe compartment (one-third, $\sim 5$ lux) and a large illuminated aversive compartment (two-thirds, $\sim 250$ lux $)$ by a partition with door $(3 \mathrm{~cm} \times 3 \mathrm{~cm})$. Each individual mouse was placed in the dark compartment, and the time spent in the light compartment within the 10 min test session was videotaped and analyzed using the EthoVision XT video tracking systems. The apparatus was thoroughly cleaned with $70 \%$ ethanol after each trial.

Hippocampal slice preparations and electrophysiological recordings. Electrophysiological recordings were performed in acutely prepared hippocampal slices as previously described (Yang et al., 2012). Briefly, mice were anesthetized with isoflurane, decapitated, and the brains quickly removed and placed in ice-cold slicing solution containing the following (in mM): 234 sucrose, $2.5 \mathrm{KCl}, 0.5 \mathrm{CaCl}_{2}, 7 \mathrm{MgCl}_{2}, 25 \mathrm{NaHCO}_{3}, 1.25$ $\mathrm{NaH}_{2} \mathrm{PO}_{4}$, and 11 glucose, $\mathrm{pH} 7.3-7.4$, and equilibrated with $95 \% \mathrm{O}_{2} / 5 \%$ $\mathrm{CO}_{2}$. Coronal hippocampal slices $(400 \mu \mathrm{m})$ were prepared using a vibratome (Leica Microsystems, VT1200S) and transferred to a holding chamber of aCSF containing the following (in $\mathrm{mm}$ ): $117 \mathrm{NaCl}, 4.7 \mathrm{KCl}$, $2.5 \mathrm{CaCl}_{2}, 1.2 \mathrm{MgCl}_{2}, 25 \mathrm{NaHCO}_{3}, 1.2 \mathrm{NaH}_{2} \mathrm{PO}_{4}$, and 11 glucose, $\mathrm{pH}$ 7.3-7.4, and equilibrated with $95 \% \mathrm{O}_{2} / 5 \% \mathrm{CO}_{2}$ and then kept at room temperature for at least $1 \mathrm{~h}$ before starting recordings.

During each electrophysiological recording session, one slice was transferred to a submersion-type recording chamber and continuously perfused with oxygenated aCSF at a flow rate of $2-3 \mathrm{ml} / \mathrm{min}$ at $\sim 32^{\circ} \mathrm{C}$ on a fixed stage. We performed extracellular field potential recordings with an Axoclamp-2B amplifier (Molecular Devices). Microelectrodes were pulled from microfiber-containing glass capillary tubings (outer diameter $=1.0 \mathrm{~mm}$ ) on a Brown-Flaming electrode puller (Sutter Instruments). The responses were low-pass-filtered at $2 \mathrm{kHz}$, sampled at 10 $\mathrm{kHz}$ using a Digidata 1320A (Molecular Devices), and analyzed with pCLAMP 8.0 software (Molecular Devices, RRID:SCR_011323). fEPSPs were evoked by electrical stimulation to Schaffer collateral/commissural fibers in the stratum radiatum of the CA1 area with a bipolar tungsten stimulating electrode at a frequency of $0.033 \mathrm{~Hz}$. The stimulation strength was adjusted to elicit a response having amplitude that was $30 \%-40 \%$ of the maximum spike-free response. The slope of fEPSP was measured from $\sim 20 \%$ to $70 \%$ of the rising phase using the least-squares regression. LTP was induced by high-frequency stimulation (HFS) consisting of two $1 \mathrm{~s}$ trains of stimuli separated by an intertrain interval of $20 \mathrm{~s}$ at $100 \mathrm{~Hz}$. The magnitude of LTP was calculated as percentage of change of fEPSP slope 50-60 min after LTP induction compared with baseline fEPSP ( 10 min before LTP induction).

Whole-cell patch-clamp recordings were made from visualized pyramidal neurons in the CA1 region of hippocampal slices using an Axopatch 200B amplifier (Molecular Devices). Data acquisition and analysis were performed using a digitizer (Digidata 1440A) and pCLAMP 8.0 software. For measurement of synaptically evoked EPSCs, a bipolar stimulating electrode was placed in the stratum radiatum of CA1 region to stimulate Schaffer collateral/commissural afferents at $0.05 \mathrm{~Hz}$, and the superfusate routinely contained gabazine (10 $\mu \mathrm{M}$, Tocris Bioscience) to block $\mathrm{GABA}_{\mathrm{A}}$ receptor-mediated inhibitory synaptic responses. The NMDAR-mediated EPSCs were recorded in $\mathrm{Mg}^{2+}$-free aCSF containing AMPA/kainate receptor antagonist CNQX (10 $\mu \mathrm{M}$, Tocris Bioscience) and gabazine $(10 \mu \mathrm{M})$ at a holding potential of $-60 \mathrm{mV}$. The composition of intracellular solution was as follows (in $\mathrm{mM}$ ): 130 cesiummethanesulfonate, 10 HEPES, 0.5 EGTA, 8 NaCl, 1 TEA, 4 Mg-ATP, 0.4 Na-GTP, 10 Na-phosphocreatine, and 5 QX-314 (Sigma-Aldrich). mEPSCs were recorded from CA1 pyramidal neurons held in voltageclamp mode at a holding potential of $-70 \mathrm{mV}$ in the presence of TTX (1 $\mu \mathrm{M}$, Alomone Labs) and gabazine (10 $\mu \mathrm{M})$, and analyzed off-line using a commercially available software (Mini Analysis 4.3; Synaptosoft, RRID: SCR_002184) as previously described (Huang et al., 2010). Detection threshold for analysis was set at twice the root-mean-square noise levels.

Preparation of synaptosomes. Synaptosomes were prepared according to the procedure as previously described (Yeh et al., 2012). The microdissected CA1 subregion was homogenized in ice-cold $\mathrm{Ca}^{2+}$ and $\mathrm{Mg}^{2+}$ free buffer (in mM as follows: $50 \mathrm{HEPES}, 100 \mathrm{NaCl}$, and $3 \mathrm{~K}$ acetate, $\mathrm{pH}$ 7.4) with RNase inhibitor $(15 \mathrm{U} / \mathrm{ml})$ and was centrifuged at $1000 \times g$ for $10 \mathrm{~min}$ to remove nuclei and cell debris. The supernatant was transferred to a new tube and centrifuged at 10,000 $\times g$ for $30 \mathrm{~min}$ to obtain the crude synaptosomal fraction and then was gently resuspended in the same buffer to the final protein concentration of $2 \mathrm{mg} / \mathrm{ml}$. All procedures were performed at $4^{\circ} \mathrm{C}$.

Preparation of subcellular fractions. Subcellular fractions were prepared as previously (Huttner et al., 1983; Lee et al., 2015). Briefly, tissue homogenate $(\mathrm{H})$ was centrifuged at $1000 \times g$ for $10 \mathrm{~min}$ to remove nuclei and other cellular debris, and the supernatant (S1) was transferred to a new tube and centrifuged at $10,000 \times g$ for 30 min to obtain the crude synaptosomal fraction (P2). The supernatant (S2) was collected and further spun at $165,000 \times g$ for $2 \mathrm{~h}$ to collect the cytosolic fraction (S3) and the light membrane/microsome-enriched fraction (P3). The P2 fraction was washed once in HBS buffer (in mM as follows: 10 HEPES-KOH, 142 $\mathrm{NaCl}, 2.4 \mathrm{KCl}, 1 \mathrm{MgCl}_{2}, 5$ glucose, 0.1 EGTA, and 0.3 PMSF, pH 7.5) and centrifuged once more at $13,000 \times g$ for $15 \mathrm{~min}$. It was then lysed in 10 volume of ice-cold $\mathrm{H}_{2} \mathrm{O}$ containing $0.3 \mathrm{~mm}$ PMSF for $30 \mathrm{~min}$, buffered with $1 \mathrm{M}$ HEPES-KOH, $\mathrm{pH} 7.4$, and centrifuged at 25,000 $\times g$ for $30 \mathrm{~min}$ to produce the synaptosomal membrane fraction (LP1). The LP1 pellet was resuspended in lysis buffer containing $1 \%$ SDS and was centrifuged at $165,000 \times g$ for $2 \mathrm{~h}$ to isolate the synaptic vesicle fraction (LP2) and soluble fraction (LS2). All procedures were performed at $4^{\circ} \mathrm{C}$.

Western blotting and immunoprecipitation. The microdissected hippocampal CA1 tissue samples were lysed in homogenate buffer (Thermo Fisher Scientific) containing a mixture of protein phosphatase and protease inhibitors, and ground with a pellet pestle (Kontes Glassware). Samples were sonicated and then centrifuged at $15,000 \times g$ at $4^{\circ} \mathrm{C}$ for 15 min. The supernatant was then assayed for total protein concentration using a BCA Protein Assay Kit (Thermo Fisher Scientific). Samples were separated in $8 \%$ or $10 \%$ SDS-PAGE gel. Proteins were transferred to a nitrocellulose membrane, washed in TBS with $0.1 \%$ Tween 20 (TBST), and blocked in TBST containing 3\% BSA for $1 \mathrm{~h}$ at room temperature. Blots were probed (overnight at $4^{\circ} \mathrm{C}$ ) with the antibodies that recognize CC2D1A (1:1000; Proteintech, catalog \#16816-1-AP, RRID: AB_2275394), GluN1 (1:1000; Santa Cruz Biotechnology, catalog \#sc1467, RRID:AB_670215), GluN2A (1:1000; Santa Cruz Biotechnology, catalog \#sc-1468, RRID:AB_670223), GluN2B (1:1000; Santa Cruz Bio- 
technology, catalog \#sc-1469, RRID:AB_670229), GluA1 (1:1000; Millipore, catalog \#AB1504, RRID:AB_2113602), postsynaptic density protein-95 (PSD-95, 1:1000; Millipore, catalog \#MAB1596, RRID: AB_2092365), synaptophysin (SYP, 1:1000; Abcam, catalog \#ab52636, RRID:AB_882786), Rho GTPase activating protein 15 (ArhGAP15, 1:1000; Proteintech, catalog \#11940-1-AP, RRID:AB_874081), p21activated kinase 1 (PAK1, 1:1000; Cell Signaling Technology, catalog \#2602, RRID:AB_330222), cofilin (1:1000; Abcam, catalog \#ab42824, RRID:AB_879739), or $\beta$-actin (1:1000; Millipore, catalog \#MAB1501, RRID:AB_2223041). The immunoblots using phosphorylation antibodies were subsequently stripped and reprobed with the following antibodies: anti-phospho-PAK1-3 antibody (1:1000; Thermo Fisher Scientific, catalog \#44-940G, RRID:AB_2533801) or anti-phospho-cofilin (Ser3) antibody (1:1000; Cell Signaling Technology, catalog \#3311, RRID: AB_330238). After further washes, membranes were incubated with HRP-conjugated secondary antibody for $1 \mathrm{~h}$ and developed using the Luminata Crescendo Western HRP Substrate (Millipore). Immunoprecipitation experiments were conducted essentially as previously reported (Huang and Hsu, 2006). Tissue homogenates ( $200 \mu$ g protein) were incubated with mouse anti-Rac1 antibody ( $1 \mu \mathrm{g}$; Millipore, catalog \#05389, RRID:AB_309712) or control anti-mouse IgG in TBS overnight at $4^{\circ} \mathrm{C}$. The antibody-protein complexes were then pelleted with protein A-magnetic beads. The complex was isolated by magnetic stand and washed four times in TBS. Proteins eluted from the beads were subjected to $10 \%$ SDS-PAGE gel and immunoblotting for anti-SUMO2/3 (1:1000; Abcam, catalog \#ab3742, RRID:AB_304041) or anti-Rac1 antibody (1: 1000; Millipore, catalog \#05-389, RRID:AB_309712), respectively. For sequential probing of the same membrane, the membrane was stripped of antibody and reprobed. Immunoblots were analyzed by densitometry using Bio-profil BioLight PC software (Vulber Lourmat). Only film exposures that were not saturated were used for quantification analysis.

Racl activation assay. The amount of activated Racl was determined by a Western blot using a Racl activation Magnetic Beads Pulldown Assay kit (Millipore, catalog \#17-10393) according to the manufacturer's instruction as previously described (Lee et al., 2011). Briefly, Rac1-GTP from CA1 tissue lysates were incubated with the Pak-1 GTPase Binding Domain (Pak-1 PBD) bond to magnetic beads for $45 \mathrm{~min}$ at $4^{\circ} \mathrm{C}$. The beads were washed with $\mathrm{Mg}^{2+}$ lysis buffer four times. Subsequently, the beads were boiled in loading buffer and separated on 10\% SDS-PAGE gels followed by immunoblotting with anti-Racl antibody to detect the presence of Rac1-GTP.

RhoA activation assay. RhoA activation was assessed by Western blot using a Rho Assay Reagent (Millipore, catalog \#14-383) according to the manufacturer's instruction. Rho-GTP from CA1 tissue lysates were incubated with the mouse Rho-binding domain of the Rho effector Rhotekin bond to glutathione-agarose for $2 \mathrm{~h}$ at $4^{\circ} \mathrm{C}$. The beads were washed four times with $\mathrm{Mg}^{2+}$ lysis buffer. The beads were then boiled in loading buffer and separated on 10\% SDS-PAGE gels followed by immunoblotting with anti-RhoA (1:1000; Millipore, catalog \#05-778, RRID: AB_309989) antibody to detect the presence of RhoA-GTP.

$q R T-P C R$. Total RNA was extracted from hippocampal CA1 tissue lysates using a Total RNA Spin kit (Bioman) as previously described (Lin et al., 2017). Reverse transcription was performed on $2 \mu \mathrm{g}$ RNA using a SuperScript cDNA synthesis kit (Invitrogen). qRT-PCR was performed on the Applied Biosystems StepOne Real-Time (StepOne: RRID: SCR_014281) using the EZtime Real-Time PCR Premix (Yeastern Biotech) according to the manufacturer's instructions. The primers used in this experiment were $C c 2 d 1 a$ : forward ( $5^{\prime}$-GCTGGCAGAGCTAAATGA GGT-3') and reverse (5'-GTGCAGACTGGTAGAGGGTTA-3'); Senp1: forward ( $5^{\prime}$-AGCTGCCCAAGAAACCAGGAAA- $\left.3^{\prime}\right)$ and reverse $\left(5^{\prime}\right.$ AATGGTCAAGCGGAATGCCT-3'); and Senp3: forward (5'-CCGGC ACCACTTACTCAAAT- $3^{\prime}$ ) and reverse (5'-AGGCGTCTAGTTGGC ACTGT- $\left.3^{\prime}\right)$. The PCRs were run for 40 cycles. Each amplification cycle included: $C c 2 d 1 a$ : denaturation at $94^{\circ} \mathrm{C}$ for $30 \mathrm{~s}$, annealing at $67^{\circ} \mathrm{C}$ for $40 \mathrm{~s}$, and extension at $72^{\circ} \mathrm{C}$ for $30 \mathrm{~s}$; Senp 1 and Senp3: denaturation at $95^{\circ} \mathrm{C}$ for $15 \mathrm{~s}$, annealing at $60^{\circ} \mathrm{C}$ for $30 \mathrm{~s}$, and extension at $72^{\circ} \mathrm{C}$ for $20 \mathrm{~s}$. All reactions were repeated in duplicate, and data were analyzed by StepOne quantification software to determine the threshold cycle above background for each reaction. The relative transcript amount of the gene of interest, which was calculated using standard curves of serial RNA dilutions, was normalized to $\beta$-actin rRNA.

Histology and quantification. For histological studies, deeply anesthetized mice were perfused transcardially with $4 \%$ PFA in $0.1 \mathrm{M} \mathrm{PBS,} \mathrm{pH}$ 7.4. After the perfusion, brains were rapidly removed, fixed in $4 \%$ PFA for $12 \mathrm{~h}$ at $4^{\circ} \mathrm{C}$, and then equilibrated in $30 \%$ sucrose for $48 \mathrm{~h}$ at $4^{\circ} \mathrm{C}$ before slicing. Coronal brain slices $(20 \mu \mathrm{m})$ containing the hippocampus were washed with $0.4 \%$ Triton X-100 and then incubated in blocking solution containing 3\% goat serum in PBS. For quantitative evaluation of neuron numbers with Nissl staining, sections were mounted directly on gelatin-coated glass slides and dried. The slides were stained with $1.0 \%$ cresyl violet, dehydrated through a series of ethanol, cleared, and coverslipped with Permount (Thermo Fisher Scientific) as previously described (Wang et al., 2017). Nissl staining within the CA1 region was quantified in images from $\sim 1.5-2.5 \mathrm{~mm}$ posterior to bregma every sixth coronal section captured at $200 \times$ magnification and digitized with an Olympus BX51 microscope coupled to an Olympus DP70 digital camera. All images were analyzed by NIH ImageJ software (RRID:SCR_003070).

Immunohistochemistry. Coronal brain slices containing the hippocampus were incubated in the primary antibodies: anti-CC2D1A (1:200; generated by the laboratory of P.L.), antineuronal nuclei (NeuN; 1:200; Millipore, catalog \#MAB377, RRID:AB_2298772), anti-CaMKII $\alpha$ (1: 1000; Thermo Fisher Scientific, catalog \#MA1-048, RRID:AB_325403), or anti-GFAP (1:200; Zymed, catalog \#13-0300, RRID:AB_2532994). Finally, sections were washed three times with $0.4 \%$ Triton X-100 in PBS and incubated in secondary AlexaFluor-488 (Invitrogen) or AlexaFluor568 antibodies (Invitrogen) for $1 \mathrm{~h}$ at room temperature. Sections were mounted with ProLong Gold Antifade Reagent (Invitrogen) with or without DAPI (Vector Laboratories). Images were acquired on an Olympus FluoView FV1000 confocal microscope. All images were analyzed by NIH ImageJ software, and all the parameters used were kept consistent during capturing.

Golgi impregnation. Anesthetized mice were transcardially perfused with PBS, and then brains were removed and placed into Golgi impregnation solution at room temperature in the dark for 2 weeks. After transferred to a $30 \%$ sucrose solution for $48 \mathrm{~h}$, brains were sectioned into 200 $\mu \mathrm{m}$ coronal sections with a vibrating microtome (VT1200S). The slices were subsequently alkalinized in $18.7 \%$ ammonia, fixed in Kodak Rapid Fix solution, dehydrated in a graded series of ethanol washes $(50 \%, 75 \%$, $95 \%$, and $100 \%$ ), cleared with xylene, mounted, and coverslipped under Permount (Thermo Fisher Scientific). Protrusion number was determined blind to genotype. At least six neurons per animal (four animals per group) were included for analysis. Images of dendritic protrusions were taken from the secondary and tertiary branches of apical dendrites ( $\sim 50 \mu \mathrm{m}$ away from the soma) of hippocampal CA1 pyramidal neurons by using the Olympus microscope equipped with a $100 \times 1.25 \mathrm{NA}$ oilimmersion objective. Multiple $Z$-stack images of CA1 neurons were collected with the help of a computer-assisted neuron tracing system (Neurolucida: RRID:SCR_001775) and further reconstructed by using ImageJ software. The numbers of spines were counted with $30 \mu \mathrm{m}$ dendrite segments and presented as the number of spines in $30 \mu \mathrm{m}$. Dendritic spines are classified into four different categories according to their morphology: (1) mushroom spines with short necks $(<1 \mu \mathrm{m})$ and bulbous heads; (2) stubby spines with heads but without necks; (3) thin spines with elongated necks ( $>1 \mu \mathrm{m})$ and small heads; and (4) filopodia with no detectable head, as described previously (Tyler and Pozzo-Miller, 2003; Wang et al., 2017). To evaluate dendritic formation for pyramidal neurons, the complexity of the dendritic arbors of each pyramidal neuron was quantified by Sholl analysis as previously described (Wang et al., 2017). A series of concentric rings at $10 \mathrm{~mm}$ intervals were centered on the soma, and the number of branches intersecting each ring was counted.

Hippocampal cannula implantation and drug injection. Mice were bilaterally implanted under isoflurane (2\%-5\%; Attane) anesthesia with 28 -gauge guide cannulas (Plastics One) in the dorsal hippocampus. The stereotaxic coordinates used were as follows [measured from bregma (in $\mathrm{mm})$ ]: anterioposterior -2.0 , mediolateral \pm 1.5 and dorsoventral -1.5 according to the description by Franklin and Paxinos (2008). The cannulas were fixed to the skull by anchoring screws and dental cement. 
Dummy cannulas (33 gauge, Plastics One) were inserted into each guide cannula at all times to prevent clogging. Mice were allowed to recover from surgery for 2 weeks before cannula infusion and behavioral training. NSC23766 trihydrochloride (NSC23766, $2.5 \mu \mathrm{g} / \mu \mathrm{l}$ in aCSF, Tocris Bioscience) or control vehicle (aCSF) were bilaterally administered into the hippocampus at the rate of $0.25 \mu \mathrm{l} / \mathrm{min}(0.5 \mu \mathrm{l} / \mathrm{side}) 15 \mathrm{~min}$ before the behavioral training using a microinfusion pump with a Hamilton syringe connected to a 33-gauge needle via polyethylene tubing. Drug dose was selected on the basis of our preliminary and published studies (Sananbenesi et al., 2007). The infusion cannula was kept in place for an additional 2 min to allow diffusion and to minimize backflow of the injectant. Histological verification of the cannula locations was performed after the completion of behavioral testing. Mice with misplaced cannulae locations were excluded from data analysis.

Experimental design and statistical analysis. Experiment 1: The expression patterns of CC2D1A in the CA1 region of the mouse hippocampus. To examine the expression profile of CC2D1A in hippocampal CA1 region, we used Western blot analysis to quantify CC2D1A protein $(n=5$ mice; see Fig. $1 A$ ) and qRT-PCR to determine $C c 2 d 1 a$ mRNA ( $n=3-7$ mice; see Fig. $1 B$ ) at different developmental stages. Subcellular fractionation by centrifugation methods was used for isolation of cell organelles from mouse hippocampal CA1 tissues to examine the expression of CC2D1A protein in various subcellular compartments of cells ( $n=4$ mice; see Fig. $1 C)$. Double immunofluorescent staining with confocal fluorescence microscopy was used to determine cell type-specific expression of CC2D1A in the CA1 region of the mouse hippocampus $(n=4$ mice in each group; see Fig. $1 D, E)$.

Experiment 2: Conditional deletion of Cc2d1 a from CA1 pyramidal neurons. We used the Cre-loxP recombination approach to conditionally delete Cc2d1a from hippocampal excitatory neurons by crossing Camk $2 \alpha$-Cre mice with $C c 2 d 1 a^{\mathrm{f} / \mathrm{f}}$ mice (see Fig. $2 A$ ). PCR was used to confirm the efficiency of Cre-loxP-mediated Cc2d1a deletion $(n=4$ mice in each group; see Fig. 2B). Western blot analysis was used to confirm the loss of CC2D1A protein expression in the cortex, CA1, and dentate gyrus (DG) of the hippocampus in cKO mice $(n=4$ mice in each group; see Fig. 2C). Double immunofluorescent staining with confocal fluorescence microscopy was used to confirm the knockdown of CC2D1A protein in CaMKII $\alpha$-expressing CA1 pyramidal neurons of cKO mice ( $n=4$ mice in each group; see Fig. $2 D)$. Cresyl violet staining was used to examine whether the total number of CAl pyramidal neurons was altered by conditional deletion of $C c 2 d 1 a$ compared with those in WT mice ( $n=4$ mice in each group; see Fig. $2 E$ ).

Experiment 3: Conditional deletion of Cc2d1a impairs performance in OLM test. To assess the role of CC2D1A in hippocampus-dependent cognitive function, we compared the long-term memory performance of WT and cKO mice in OLM test. Behavioral measures included discrimination index (WT: $n=10$ mice; cKO: $n=16$ mice; see Fig. $3 A$ ) and total exploration time (WT: $n=10$ mice; cKO: $n=16$ mice; see Fig. $3 B$ ). We also used $C c 2 d 1 a^{\mathrm{f} / \mathrm{f}}$ mice in combination with Cre recombinasemediated gene deletion in a localized fashion through bilateral stereotaxic injections of AAV-GFP or AAV-Cre-GFP adenoviral vectors targeting the CA1, under control of the CaMKII $\alpha$ promoter. $C c 2 d 1 a^{\mathrm{f} / \mathrm{f}}$ mice injected with AAV-GFP served as controls. Three weeks after stereotaxic injection of AAV-GFP or AAV-Cre-GFP, mice were subjected to behavioral test. The successful transduction of AAV-Cre-GFP or AAVGFP was confirmed by costaining for the excitatory neuron-specific marker CaMKII $\alpha$ ( $n=4$ mice in each group; see Fig. $3 C)$. Western blot analysis was used to confirm the specific loss of CC2D1A expression in the CA1 region, 3 weeks following the stereotactic injection of AAV-CreGFP (AAV-GFP: $n=4$ mice; AAV-Cre-GFP: $n=4$ mice; see Fig. $3 D$ ). We compared the performance of AAV-GFP- and AAV-Cre-GFPtreated mice in OLM test. Behavioral measures included discrimination index (see Fig. 3E) and total exploration time (see Fig. 3F) (AAV-GFP: $n=8$ mice; AAV-Cre-GFP: $n=9$ mice).

Experiment 4: Conditional deletion of Cc2d1a alters anxiety-like behavior. We examined whether conditional deletion of $C c 2 d 1 a$ may alter anxiety-like behavior. Three behavioral paradigms, including the OF, EPM, and LDB tests, were used to evaluate changes in anxiety-like behavior. Behavioral measures included total distance traveled (see Fig.
$4 A$ ), time in central zone (see Fig. 4B), time in close arms (see Fig. 4C), time in open arms (see Fig. $4 D$ ), number of entries into open arms (see Fig. $4 E$ ) (WT: $n=14$ mice; cKO: $n=18$ mice), and the time spent in the light compartment (see Fig. $4 F$ ) (WT: $n=7$ mice; cKO: $n=7$ mice).

Experiment 5: Conditional deletion of Cc2d1a impairs LTP maintenance at Schaffer collateral-CA1 synapses. To determine whether CC2D1A is directly involved in the regulation of synaptic transmission, we compared stimulus-response curves of fEPSPs (WT: $n=4$ slices from 4 mice; cKO: $n=5$ slices from 4 mice; see Fig. $5 A$ ) and paired-pulse facilitation (WT: $n=6$ slices from 4 mice; cKO: $n=8$ slices from 5 mice; see Fig. $5 B$ ) at Schaffer collateral-CA1 synapses in slices from WT and cKO mice. We further examined whether the induction of LTP in the CA1 was affected in cKO mice. LTP was induced by HFS, consisting of two $1 \mathrm{~s}$ trains of stimuli separated by an intertrain interval of $20 \mathrm{~s}$ at $100 \mathrm{~Hz}$ (WT: $n=9$ slices from 5 mice; cKO: $n=7$ slices from 4 mice; see Fig. $5 C, D)$.

Experiment 6: Conditional deletion of Cc2d1a on expression of AMPAR or NMDAR subunits in hippocampal CA1 region. To elucidate whether $C c 2 d 1 a$ deletion alters the expression of AMPAR or NMDAR subunits, we measured the protein expression patterns of AMPAR and NMDAR subunits in the hippocampal CA1 region of WT and cKO mice by Western blot analysis. The expression levels of AMPAR subunit, GluA1, and three major NMDAR subunits, GluN1, GluN2A, and GluN2B, in whole tissue homogenates (see Fig. $6 \mathrm{~A}$ ) or the synaptosomal fraction from hippocampal CA1 tissue lysates (see Fig. $6 B$ ) were compared $(n=8$ mice in each group). To further examine the role of CC2D1A in the regulation of spontaneous transmission at excitatory synapses on CA1 pyramidal neurons, we compared the frequency and amplitude of mEPSCs (WT: $n=9$ neurons from 5 mice; cKO: $n=10$ neurons from 5 mice; see Fig. $6 C$ ). To further elucidate the role of CC2D1A in the regulation of NMDAR function, we also examined whether $C c 2 d 1 a$ deletion alters evoked NMDARmediated EPSCs (WT: $n=8$ neurons from 4 mice; cKO: $n=10$ neurons from 5 mice; see Fig. 6D).

Experiment 7: Conditional deletion of Cc2d1a alters dendritic morphology of CA1 pyramidal neurons. To examine whether conditional deletion of $C c 2 d 1 a$ may alter dendritic geometry and spine density, we used GolgiCox staining to visualize individual CA1 pyramidal neurons in WT and cKO mice and analyzed the complexity of their dendritic trees (WT: $n=$ 22 neurons from 4 mice; cKO: $n=28$ neurons from 4 mice; see Fig. $7 A-C)$. The density of dendritic spine was detected on secondary and tertiary branches of apical dendrites of CA1 pyramidal neurons (WT: $n=$ 58 neurons from 5 mice; cKO: $n=42$ neurons from 5 mice; see Fig. $7 D, E)$. The effect of conditional deletion of $C c 2 d 1 a$ on the proportion of dendritic spine types was examined (WT: $n=58$ neurons from 5 mice; cKO: $n=42$ neurons from 5 mice; see Fig. $7 F$ ).

Experiment 8: Conditional deletion of Cc2d1a results in hyperactive Rac1-PAK-cofilin signaling pathway. To investigate whether Racl signaling is dysregulated in cKO mice, we compared the expression levels of active GTP-bound Rac1 (Racl-GTP) in hippocampal CA1 tissue homogenates from WT and cKO mice by using Western blot analysis (WT: $n=8$ mice; cKO: $n=9$ mice; see Fig. $8 A$ ). To examine whether RhoA signaling is altered in $\mathrm{cKO}$ mice, we compared the expression levels of active GTP-bound RhoA (RhoA-GTP) in hippocampal CAl tissue homogenates from WT and cKO mice by using Western blot analysis (WT: $n=6$ mice; $c K O: n=6$ mice; see Fig. $8 B$ ). We further examined whether Rac1-PAK-cofilin signaling is increased in $\mathrm{cKO}$ mice by assessing the phosphorylation state of PAK1-3 and cofilin in hippocampal CA1 tissue homogenates from WT and cKO mice by using Western blot analysis (WT: $n=6$ mice; cKO: $n=6$ mice; see Fig. $8 C$ ).

Experiment 9: Conditional deletion of Cc2d1a increases Rac1 SUMOylation and activity through downregulating SUMO-specific protease 1 (SENP1) and 3 (SENP3) expression. To investigate whether Cc2d1a deletion alters expression of the ArhGAP15, we compared the expression levels of ArhGAP15 in hippocampal CA1 tissue homogenates from WT and cKO mice by using Western blot analysis (WT: $n=6$ mice; $\mathrm{cKO}: n=$ 6 mice; see Fig. 9A). To determine whether $C c 2 d 1 a$ deletion activates Rac1 through increasing Racl SUMOylation, we performed immunoprecipitation experiments. The Racl SUMOylation levels were determined by Rac1 pull-down followed by Western blotting analysis using an anti-SUMO2/3 antibody $(n=5$; see Fig. $9 B)$. To examine whether 
Cc2d1 $a$ deletion alters the expression of SENP1 and SENP3 in hippocampal CA1 region, we used Western blot analysis to quantify SENP1 and SENP3 protein (WT: $n=6$ mice; cKO: $n=5$ mice; see Fig. $9 C$ ) and qRT-PCR to determine Senp 1 and Senp 3 mRNA (WT: $n=6$ mice; cKO: $n=7$ mice; see Fig. 9D) in the hippocampal CA1 region of WT and cKO mice.

Experiment 10: NSC23766 rescues LTP and OLM deficits in cKO mice. To verify the most appropriate NSC23766 concentration to manipulate Racl activity, we performed a set of experiments to determine basal Rac1 activity in the CA1 region of hippocampal slices from WT and cKO mice in the presence of different concentrations of NSC23766 (see Fig. 10A). We determined the effect of NSC23766 $(10 \mu \mathrm{M})$ on the magnitude of LTP in slices from WT ( $n=7$ slices from 5 mice) and cKO mice $(n=7$ slices from 5 mice; see Fig. $10 B, C$ ). We compared the vehicle (aCSF) and NSC23766 treatment $(2.5 \mu \mathrm{g} / \mu \mathrm{l}$, bilateral intrahippocampal injection) on long-term OLM performance in WT and cKO mice. Behavioral measures included discrimination index (see Fig. 10D) and total exploration time (see Fig. 10E) (WT-Veh: $n=7$ mice; WT-NSC: $n=9$ mice; cKOVeh: $n=7$ mice, cKO-NSC: $n=7$ mice).

Experiment 11: Effect of NSC23766 treatment on dendritic morphology of CA1 pyramidal neurons from cKO mice. To examine whether NSC23766 improved synaptic function in $\mathrm{cKO}$ mice by restoring the dendritic complexity of CA1 pyramidal neurons, we used Golgi-Cox staining to visualize individual CA1 pyramidal neurons in cKO-vehicle and cKONSC23766 mice and analyzed the complexity of their dendritic trees (cKO-Veh: $n=21$ neurons from 4 mice; cKO-NSC23766: $n=24$ neurons from 4 mice; see Fig. 11A-C).

Statistical analysis. No statistical methods were used to predetermine sample size, but our sample sizes were based up previous work of a similar nature by our laboratory (Wang et al., 2017; Lin et al., 2018). The results are presented as mean \pm SEM. All statistical analyses were performed using the Prism 6 software (GraphPad; RRID:SCR_002798). To compare the difference between the two population means, we first determined whether the data were normally distributed using the ShapiroWilk test. For normal distributions, we calculated $p$ values using twotailed unpaired Student's $t$ test; whereas for non-normal distributions, we used Mann-Whitney $U$ test. Because the data of LTP magnitudes were not normally distributed, the Mann-Whitney $U$ test was used to compare differences between two independent groups. The significance of the difference between multiple groups was calculated by two-way ANOVA followed by Bonferroni's post hoc analyses. Unless otherwise specified, $n$ indicates the number of animals used. Differences were considered as significant at $p \leq 0.05$.

\section{Results}

\section{Expression pattern of CC2D1A in the mouse hippocampus during development}

The open-source Allen brain atlas highlights Cc2dla mRNA in the hippocampus. Toward understanding the functional role of CC2D1A in the hippocampus, we first examined the expression profile of CC2D1A in the developing and adult mouse hippocampus using an antibody specific for CC2D1A. Relative amount of CC2D1A protein expression in hippocampal CA1 tissues was low during late developmental stages (embryonic day 18 and postnatal day 1), gradually increased up to postnatal 14 and then remained constant in adulthood (Fig. 1A). The qRT-PCR study showed that the amount of the Cc2dla mRNA gradually increased after birth and reached maximum in adulthood (Fig. 1B). We further examined the expression of CC2D1A protein in various subcellular compartments of mouse hippocampal CA1 tissues using subcellular fractionation method. The reliability of this method was confirmed by PSD-95 and SYP as markers for the subcellular compartments as described previously (Huttner et al., 1983; Lee et al., 2015). As shown in Figure 1C, CC2D1A was detected in the nuclei and large debris (P1), cytosol (S2, S3), crude synaptosomes (P2), light membranes (P3), synaptosomal membranes (LP1), and synaptic vesicle-enriched fraction (LP2), but not in the synaptosomal cytosol (LS2).

We next used immunolocalization together with confocal fluorescence microscopy to determine cell type-specific expression of CC2D1A in the mouse hippocampus. Double immunofluorescent staining with the mature neuronal marker NeuN revealed that nearly all of the CC2D1A-expressing cells were positive for neuronal nuclear antigen NeuN in pyramidal layers of the hippocampal CA1 region (Fig. 1D). In contrast, we did not detect CC2D1A immunoreactivity in glial cells, which were identified by antibody directed against the glial marker GFAP and showed typical star-shaped astrocyte morphology (Fig. 1D), indicating that CC2D1A expression is essentially confined to neurons. To determine the identity of CC2D1A-expressing neurons, double immunofluorescent staining was performed with antibody against CaMKII $\alpha$, a marker of excitatory neurons. Our results indicated that CC2D1A-expressing neurons are labeled with CaMKII $\alpha$ in the hippocampal CA1 region (Fig. 1E). To investigate whether GABAergic interneurons in the hippocampus also express CC2D1A, we used GAD67-GFP knock-in mice, in which GABAergic interneurons are specifically labeled with GFP fluorescence. We also found a number of GAD67-GFP-positive cells that express CC2D1A (Fig. 1E). These results suggest that CC2D1A is abundantly expressed in both excitatory and inhibitory neurons in the mouse hippocampal CAl region.

\section{Conditional deletion of $C c 2 d 1 a$ from hippocampal excitatory neurons}

We generated a conditional $C c 2 d 1 a$ mouse mutant by flanking the 12-14 coding exons with loxP sites. To conditionally delete $C c 2 d 1 a$ from hippocampal excitatory neurons, $C c 2 d 1 a^{\mathrm{f} / \mathrm{f}}$ mice were crossed with Camk $2 \alpha$-Cre transgenic mice to generate cell type-specific $C c 2 d 1 a$ cKO mice using the cre-loxP recombination approach (Fig. 2A). PCR screening of mouse genomic tail DNA confirmed heterozygous $\left(C c 2 d 1 a^{\mathrm{f} /+}\right.$; Camk $2 \alpha$-Cre $)$ and homozygous (Cc2d1a $a^{\mathrm{fff}}$; Camk $2 \alpha$-Cre) cKO mice (Fig. $\left.2 B\right)$. The cKO mice showed no gross anatomical brain abnormalities (data not shown). Western blot analysis also confirmed a reduction in CC2D1A protein expression in the cortex, CA1, and DG of the hippocampus in cKO mice (Fig. 2C). In WT mice, our immunohistochemical analysis indicated that $\mathrm{CaMKII} \alpha$-expressing cells were positive for CC2D1A in the hippocampal CA1 region. In cKO mice, we did not detect CC2D1A immunoreactivity in CaMKII $\alpha$-expressing cells (Fig. 2D). Histological assessment using cresyl violet staining showed that $C c 2 d 1 a$ deletion does not significantly affect the total number of neurons in the stratum pyramidale of the hippocampal CA1 region compared with that of WT littermates $\left(t_{(6)}=1.22, p=0.27, n=4\right.$ mice in each group; two-tailed unpaired Student's $t$ test; Fig. 2E).

\section{Conditional deletion of $C c 2 d 1 a$ impairs long-term OLM performance}

We next determined whether conditional deletion of $C c 2 d 1 a$ from hippocampal excitatory neurons may alter long-term memory performance in OLM test, a form of associative learning that engages the hippocampus (Mumby et al., 2002; Haettig et al., 2011). We found that $C c 2 d 1 a$ deletion leads to a reduction in time spent exploring the object in the novel location to the one in the original location, as shown by a significant decrease in the discrimination index compared with WT mice $\left(t_{(24)}=3.09, p=\right.$ 0.005, WT: $n=10$; cKO: $n=16$; two-tailed unpaired Student's $t$ test; Fig. $3 A$ ). We did not observe significant differences between WT and cKO mice in the total exploration time $\left(t_{(24)}=0.04, p=\right.$ 
A

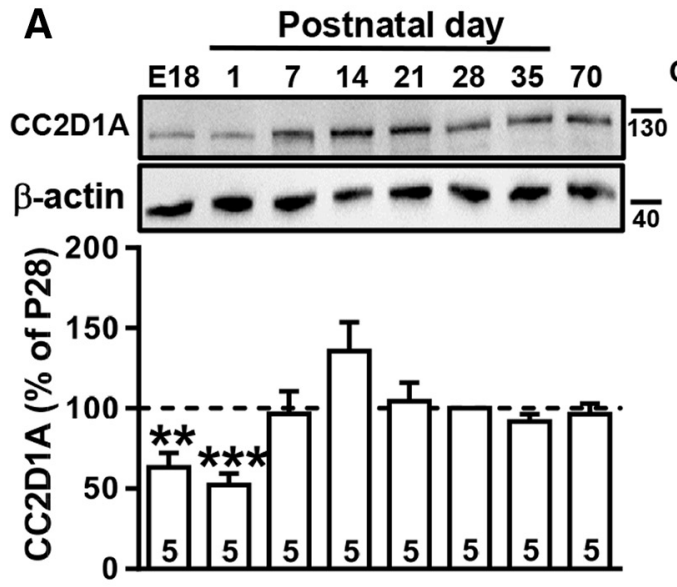

B

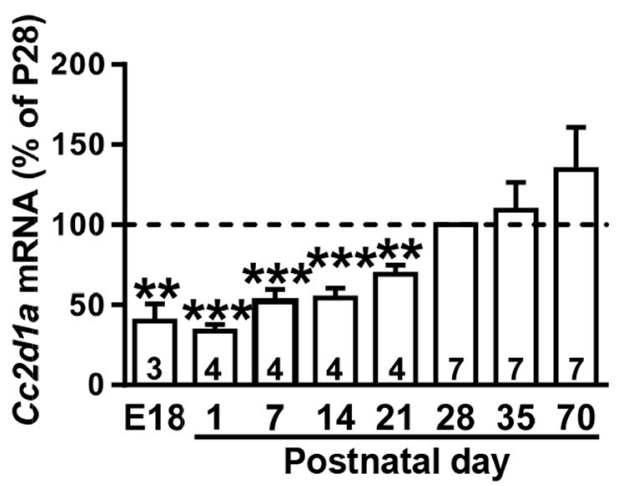

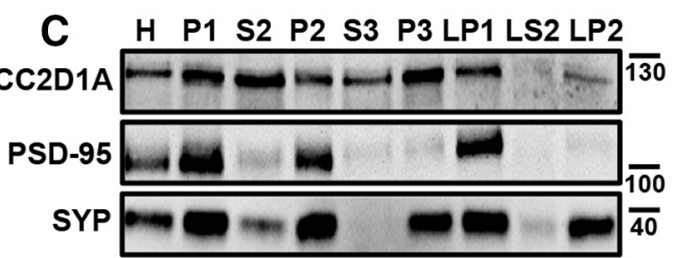

D
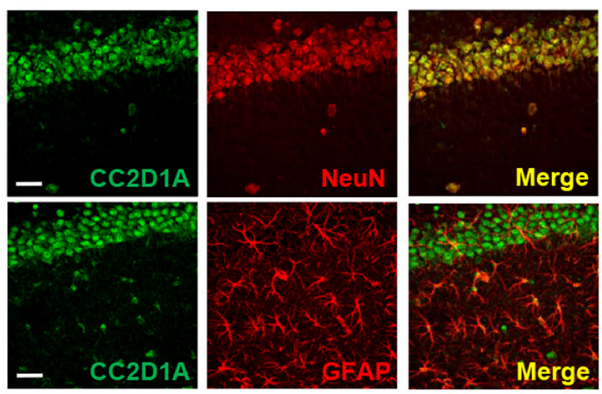

E
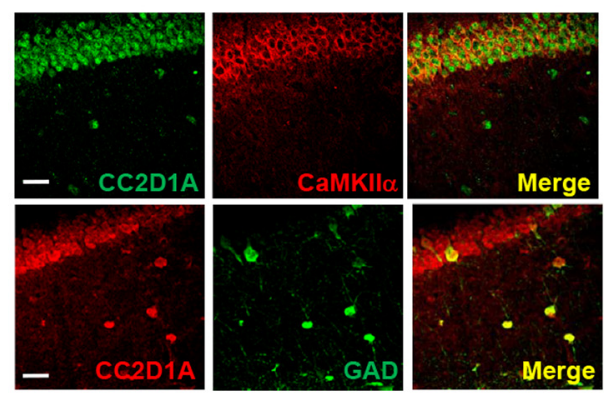

Figure 1. The expression patterns of CC2D1A in the CA1 region of the mouse hippocampus. $A$, Representative immunoblotting and summary bar graph showing the relative expression of CC2D1A protein in embryonic day $(\boldsymbol{E}) 18$ and postnatal day 1-70 mouse hippocampal CA1 tissue lysates. B, Summary bar graph showing the relative expression of Cc2d1a mRNA in E18 and postnatal day 1-70 mouse hippocampal CA1 region. C, Representative immunoblotting analysis showing the subcellular localization of CC2D1A in P35 mouse hippocampal CA1 lysates. H, Homogenates; P1, nuclei and large debris; P2, crude synaptosomes; P3, light membranes; S2, supernatant after P2 precipitation; S3, cytosol; LP1, synaptosomal membranes; LP2, synaptic vesicle-enriched fraction; LS2, synaptosomal cytosol. Subcellular fractionations were confirmed by immunoblotting with anti-PSD-95 and SYP antibodies, respectively. Data were replicated in 4 mice. D, Doubled-labeled confocal immunofluorescent images showing the colocalization of CC2D1A (green) and the neuronal marker NeuN (red; top) or glial marker GFAP (red; bottom) in the CA1 of the naive mouse hippocampus. Data were replicated in 4 mice. Scale bar, $20 \mu \mathrm{m}$. E, Top, Doubled-labeled confocal immunofluorescent images showing the colocalization of CC2D1A (green) and CaMKIl $\alpha$ (red; top) in the CA1 of the naive mouse hippocampus. Bottom, Doubled-labeled confocal immunofluorescent images showing the colocalization of CC2D1A (green) and GAD (red) in hippocampal area CA1 of GAD67-GFP knock-in mice. Data were replicated in 4 mice. Scale bar, $20 \mu \mathrm{m}$. The total number of animals examined is indicated by $n$ in parentheses. Data are mean \pm SEM. ${ }^{* *} p<0.01$, compared with postnatal day 28 (two-tailed unpaired Student's $t$ test). ${ }^{* * *} p<0.001$, compared with postnatal day 28 (two-tailed unpaired Student's $t$ test).

0.97, WT: $n=10$; cKO: $n=16$; two-tailed unpaired Student's $t$ test; Fig. $3 B$ ), indicating that $C c 2 d 1 a$ deletion does not affect predisposition to explore objects.

Because $C c 2 d 1$ a deletion in cKO mice was not restricted to the CA1, the loss of CC2D1A function in other hippocampal or forebrain regions might also contribute to the observed defect in the persistence of long-term OLM. To circumvent this limitation, in a subset of experiments, we used $C c 2 d 1 a^{\mathrm{f} / \mathrm{f}}$ mice in combination with Cre recombinase-mediated gene deletion in a localized fashion through bilateral stereotaxic injections of AAV-Cre-GFP or control AAV-GFP adenoviral vectors targeting the CA1, under the control of CaMKII $\alpha$ promoter that theoretically restricts expression to excitatory neurons. The successful transduction of AAV-Cre-GFP or AAV-GFP was confirmed by costaining for CaMKII $\alpha$ (Fig. 3C). Western blot analysis confirmed the specific loss of CC2D1A protein expression in the CA1 region $\left(t_{(6)}=7.21\right.$, $p<0.0001$; two-tailed unpaired Student's $t$ test), 3 weeks following the stereotactic injection of AAV-Cre-GFP (Fig. 3D). AAVGFP and AAV-Cre-GFP mice were then subjected to OLM test. Consistent with the results obtained from cKO mice, we found that AAV-Cre-GFP mice exhibited significantly reduced discrim- ination index compared with AAV-GFP mice $\left(t_{(15)}=3.13, p=\right.$ 0.007; AAV-GFP: $n=8$; AAV-Cre-GFP: $n=9$; two-tailed unpaired Student's $t$ test; Fig. $3 E$ ), whereas no differences between the groups in total exploration of time were observed $\left(t_{(15)}=\right.$ 0.30, $p=0.77$, AAV-GFP: $n=8$; AAV-Cre-GFP: $n=9$; twotailed unpaired Student's $t$ test; Fig. $3 F$ ). Together, these results suggest that CA1 Cc2d1a deletion impairs long-term OLM performance.

Conditional deletion of $C c 2 d 1 a$ alters anxiety-like behavior It has been shown that mutations in the human $c c 2 d 1 a$ gene may lead to the development of autism spectrum disorder-relevant behavioral phenotypes (Manzini et al., 2014). We thus examined whether Cc2d1a deletion may alter anxiety-like behavior. Three widely used behavioral tests (the OF, EPM, and LDB) were used to evaluate changes in anxiety-like behavior. Indeed, in the OF test, $\mathrm{cKO}$ mice showed a significant increase in total distance traveled $\left(t_{(30)}=3.62, p=0.001 ; n=18\right.$; two-tailed unpaired Student's $t$ test; Fig. $4 A$ ) and spent less time in the central zone of the field $\left(t_{(30)}=2.79, p=0.009 ; n=18\right.$; two-tailed unpaired Student's $t$ test; Fig. $4 B)$ compared with WT mice $(n=14)$, indi- 
A
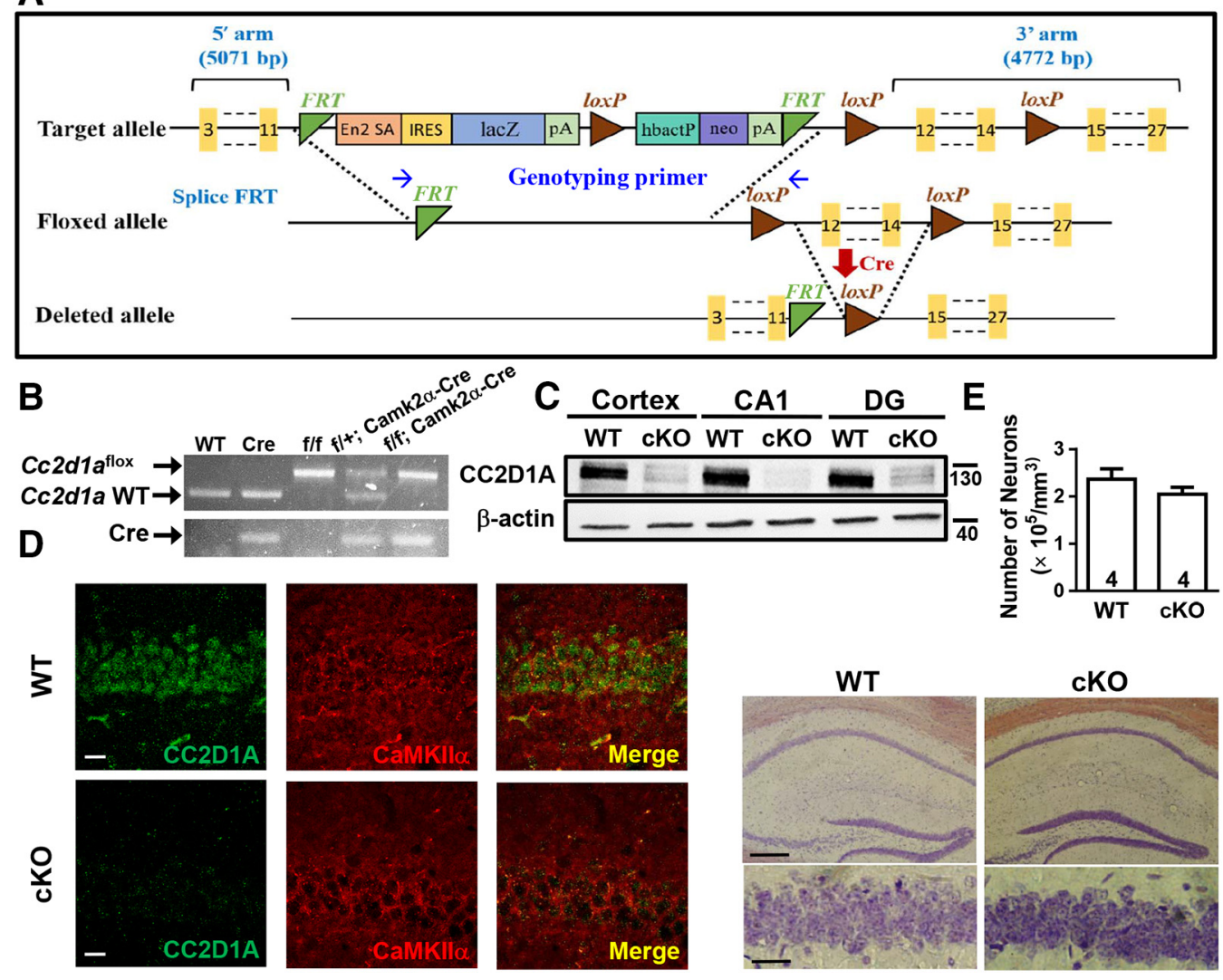

Figure 2. Conditional deletion of Cc2d1 $a$ in the excitatory neurons of mouse hippocampus. $A$, Schematic representation of mouse recombinant $C(2 d 1$ a construct; a floxed $C(2 d 1 a$ allele allows the Cre-mediated deletion of exon 12-14. Blue arrows indicate the primers' annealing positions. B, PCR screening of tail-derived genomic DNA for selection of WT, Camk2 $\alpha$-Cre, $C\left(2 d 1 a^{\mathrm{f} / \mathrm{f}}\right.$, heterozygous $\left(\mathrm{CC} 2 \mathrm{d1} a^{\mathrm{f} /+}\right.$; Camk2 $\alpha$-Cre), and homozygous (Cc2d1 $a^{\mathrm{f} / \mathrm{f}}$; Camk2 $\alpha$-Cre) cKO mice. C, Western blot detection of CC2D1A protein levels in cortex, CA1, and DG tissue lysates from mice of the indicated genotypes. D, Representative immunofluorescent images of CC2D1A (green) and CaMKIl $\alpha$ (red) expression in the CA1 region of the hippocampus from WT and cK0 mice. Scale bars, $20 \mu \mathrm{m}$. $\boldsymbol{E}$, Representative photographs with cresyl violet staining of the CA1 region showing that the number of pyramidal neurons was not significantly affected by C( $2 d 1 a$ deletion compared with age-matched WT mice. Group data showing the summary results from 4 mice of each group at 10 weeks of age. Scale bars: Top, $200 \mu \mathrm{m} ;$ Bottom, $10 \mu \mathrm{m}$. Data are mean \pm SEM. The total number of animals examined is indicated by $n$ in parentheses.

cating an increase in anxiety-like behavior. Strikingly, in the EPM test, $\mathrm{CKO}$ mice spent less time in the closed $\operatorname{arms}\left(t_{(30)}=2.87, p=\right.$ 0.008; $n=18$; two-tailed unpaired Student's $t$ test; Fig. $4 C)$ but same amounts of time in the open arms $\left(t_{(30)}=1.73, p=0.09\right.$; $n=18$; two-tailed unpaired Student's $t$ test; Fig. $4 D$ ), and showed a significant increase in number of entries into the open arms $\left(t_{(30)}=2.91, p=0.007 ; n=18\right.$; two-tailed unpaired Student's $t$ test; Fig. $4 E)$ compared with WT mice $(n=14)$, indicating an anxiolytic-like phenotype. In the LDB test, $\mathrm{cKO}$ mice spent less time in the light compartment $\left(t_{(12)}=3.94, p=0.002 ; n=7\right.$; two-tailed unpaired Student's $t$ test; Fig. $4 F$ ) compared with WT mice $(n=7)$, indicating an increase in anxiety-like behavior. Considering that the reason for the inconsistent effects of $C c 2 d 1 a$ deletion on these three tests for anxiety-like behavior remains unclear, these results could only be concluded that $C c 2 d 1 a$ deletion alters anxiety-like behavior.

\section{Conditional deletion of $C c 2 d 1 a$ impairs the maintenance of LTP}

To elucidate the potential neurophysiological basis of cognitive impairment in cKO mice, we compared the basal synaptic transmission and the induction of long-term synaptic plasticity at Schaffer collateral-CA1 synapses in hippocampal slices from WT and cKO mice. As shown in Figure 5A, stimulus-response curves of fEPSPs were similar in slices from WT and cKO mice (group $\times$ stimulus intensity: $F_{(11,84)}=0.61, p=0.82 ; \mathrm{WT}: n=4$ slices from 4 mice; cKO: $n=5$ slices from 4 mice; two-way repeatedmeasures ANOVA). To determine whether Cc2d1a deletion alters the presynaptic function, we examined the paired-pulse facilitation, a transient form of presynaptic plasticity induced by two closely spaced stimuli. As shown in Figure $5 B$, pairs of presynaptic fiber stimulation pulses delivered at all interpulse intervals evoked nearly identical amounts of paired-pulse facilitation ratio in slices from WT and cKO mice $\left(F_{(5,72)}=0.24, p=0.95\right.$; WT: $n=6$ slices from 4 mice; cKO: $n=8$ slices from 5 mice; two-way repeated-measures ANOVA). These results suggest that the basal synaptic transmission and presynaptic glutamate release at Schaffer collateral-CA1 synapses remain normal after conditional deletion of Cc2d1a from hippocampal CA1 excitatory neurons.

We next compared the magnitude of hippocampal CA1 LTP in slices from WT and cKO mice. LTP was induced by using a protocol consisting of two $1 \mathrm{~s}$ trains of $100 \mathrm{~Hz}$ stimuli separated by an intertrain interval of $20 \mathrm{~s}$. In slices from WT mice, this protocol induced a robust LTP (50-60 min after HFS: $157.5 \pm 6.0 \%$ of baseline; $p<0.05 ; n=9$ slices from 5 mice; Mann-Whitney $U$ test), whereas a significant reduction in the magnitude of LTP was observed in slices from cKO mice (50-60 min after HFS: $137.3 \pm 6.9 \%$ of baseline; $p=0.04 ; n=7$ slices from 4 mice; Mann-Whitney $U$ test; Fig. $5 C, D)$. Given the fact that the magnitudes of LTP during the 

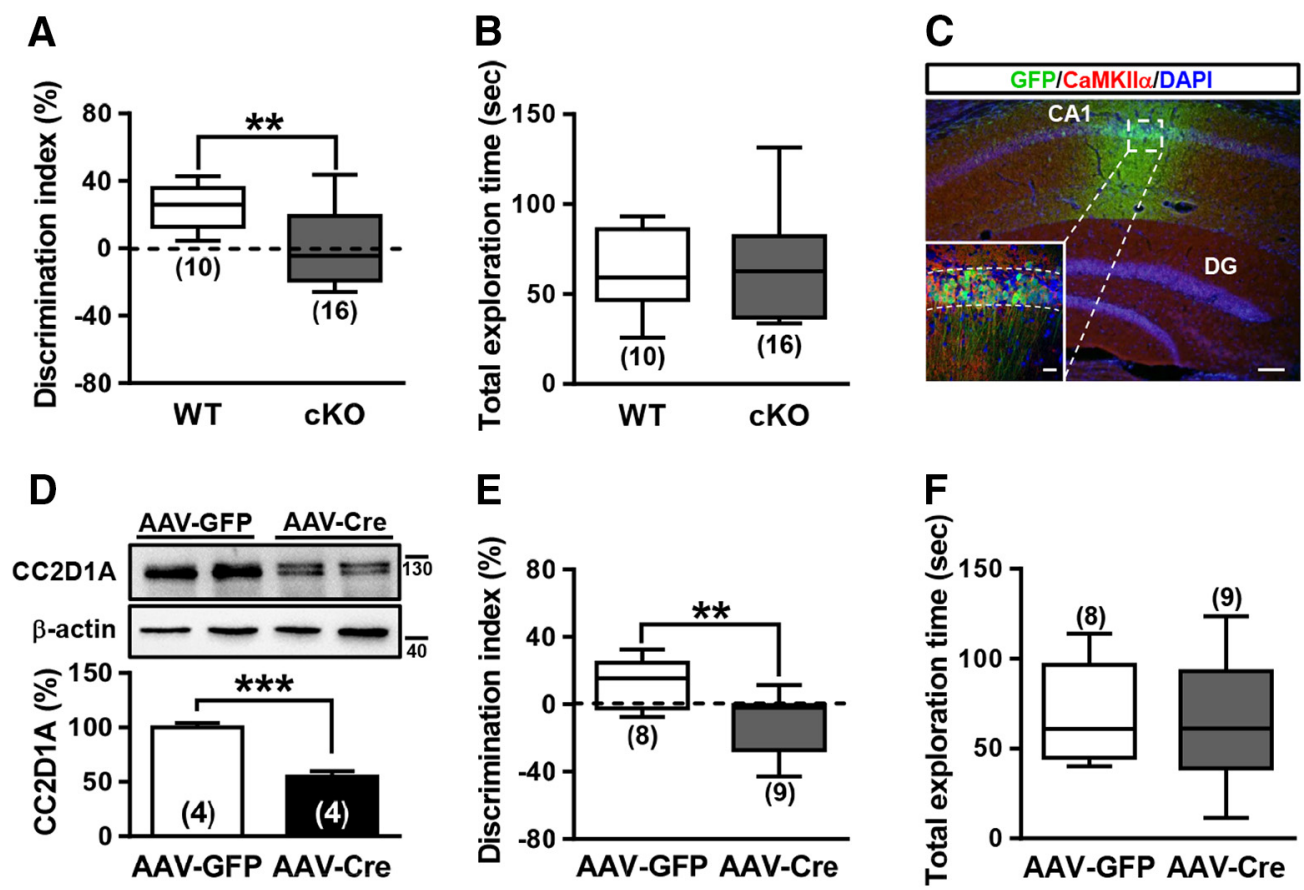

Figure 3. Conditional deletion of (C2d1a impairs performance in OLM test. $A$, The CKO mice displayed a decreased discrimination index in OLM test compared with WT mice. $B$, The cKO and WT mice showed similar total object exploration time. C, Representative photograph showing the expression of AAV-Cre-GFP (green) in the CA1 and immunolabeled with CaMKIII $\alpha$ (red) and DAPI (blue). Scale bar, $100 \mu \mathrm{m}$. Inset, High magnification of the boxed area. Scale bar, $20 \mu \mathrm{m}$. D. Representative immunoblotting and summary bar graph depicting levels of CC2D1A in hippocampal CA1 tissue homogenates from AAV-GFP- and AAV-Cre-GFP-treated C(2d17a/f mice. E, AAV-Cre-GFP-treated C(2d17 ${ }^{\mathrm{f} / \mathrm{f}}$ mice displayed a decreased discrimination index in OLM test compared with AAV-GFP-treated $\left(\mathrm{C} 2 \mathrm{~d} 1 a^{\mathrm{fff}}\right.$ mice. F,AAV-GFP-and AAV-Cre-GFP-treated C(2d1 $a^{\mathrm{fff}}$ mice showed similar total object exploration time. Data are mean \pm SEM. The total number of animals examined is indicated by $n$ in parentheses. ${ }^{* *} p<0.01$, compared with WT or AAV-GFP-treated group (two-tailed unpaired Student's $t$ test). ${ }^{* * *} p<0.001$, compared with AAV-GFP treated group (two-tailed unpaired Student's t test).
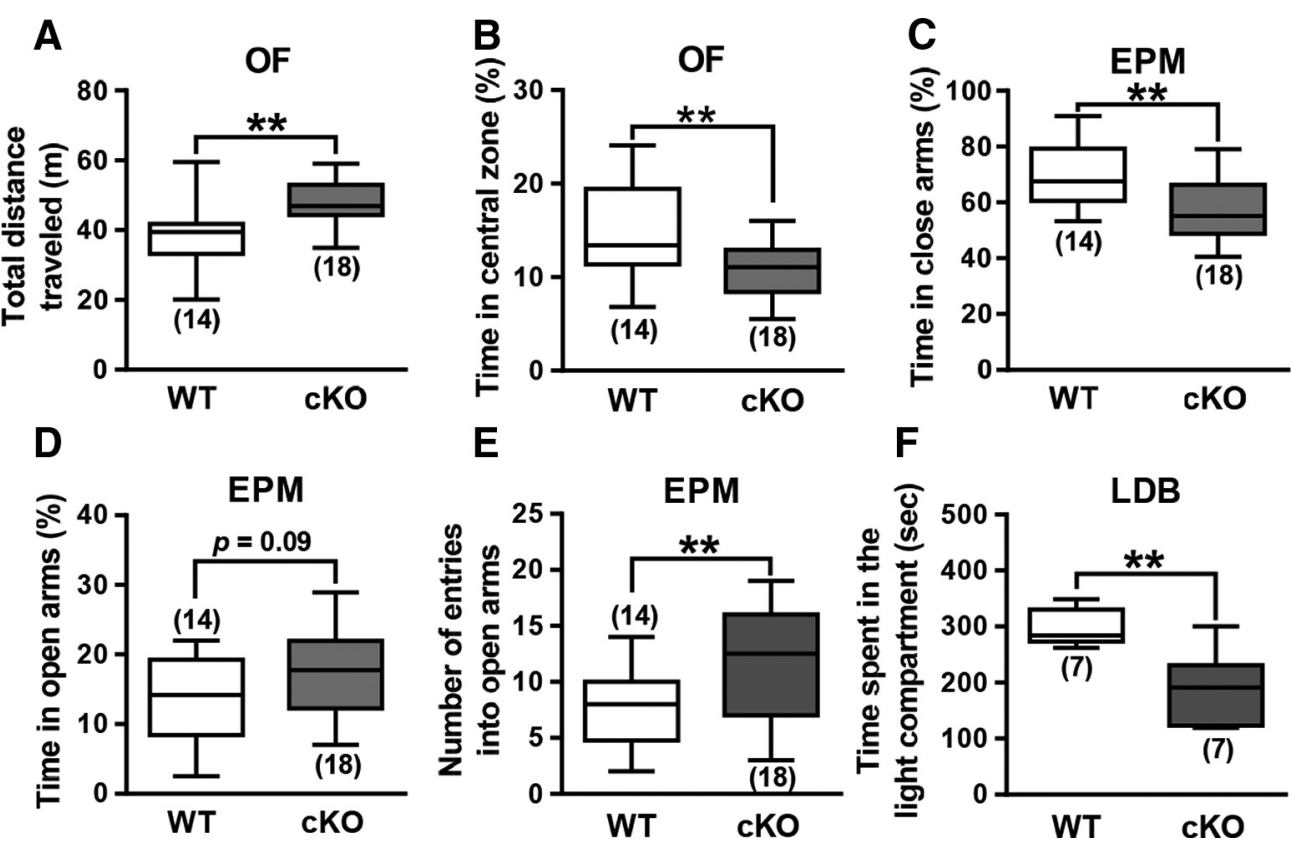

Figure 4. Conditional deletion of (c2d1a increases anxiety-like behavior. $A, B, B$ ar graph comparing the performance of WT and cK0 mice on the total distance traveled ( $A$ ) and the time spent in central zone $(\boldsymbol{B})$ in the OF test. $\boldsymbol{C}-\boldsymbol{E}$, Bar graph comparing the performance of WT and cKO mice on the percentage of time spent in the open $(\boldsymbol{C})$ and closed arms $(\boldsymbol{D})$ and number of entries into open arms $(\boldsymbol{E})$ in the EPM test. $\boldsymbol{F}$, Bar graph comparing the performance of WT and cKO mice on the time spent in the light compartment in the LDB test. Data are mean \pm SEM. The total number of animals examined is indicated by $n$ in parentheses. ${ }^{* *} p<0.01$, compared with WT group (two-tailed unpaired Student's $t$ test).

first 10 min after HFS were similar in slices from WT and cKO mice, we suggest that $C c 2 d 1 a$ deletion selectively suppresses the maintenance of LTP, but not its induction.

To assess whether $C c 2 d 1 a$ deletion may alter the expression of AMPAR or NMDAR subunits, we measured the protein expres- sion patterns of AMPAR and NMDAR subunits in the hippocampal CA1 region of WT and cKO mice by Western blot analysis. The deletion efficiency of cKO mice was confirmed by the dramatic reduction in CC2D1A protein levels. As shown in Figure $6 \mathrm{~A}$, we did not observe significant differences between WT and 
cKO mice in the expression levels of AMPAR subunit, GluA1, and three major NMDAR subunits, GluN1, GluN2A, and GluN2B, in whole tissue homogenates of the hippocampal CA1 region $(p>0.05$; $n=8$ mice in each group; two-tailed unpaired Student's $t$ test). Because the functional AMPARs and NMDARs are thought to reside within synapses, we further examined whether $C c 2 d 1 a$ deletion could alter the subunit composition of synaptic AMPARs and NMDARs. Similar to what we observed in whole tissue homogenates, cKO mice did not show significant changes in protein levels of GluA1, GluN1, GluN2A, and GluN2B in the synaptosomal fraction from hippocampal CA1 tissues compared with those from WT mice $(p>0.05 ; n=8$ in each group; two-tailed unpaired Student's $t$ test; Fig. $6 B)$.

We also analyzed mEPSCs recorded from CA1 pyramidal neurons in slices from WT and cKO mice. We found that the frequency $\left(t_{(17)}=2.52, p=0.02\right.$; WT: $n=9$ neurons from 6 mice; cKO: $n=10$ neurons from 6 mice; unpaired Student's $t$ test) but not the amplitude $\left(t_{(17)}=\right.$ $0.82, p=0.42$; WT: $n=9$ neurons from 6 mice; cKO: $n=10$ neurons from 7 mice; unpaired Student's $t$ test) of mEP-

SCs was significantly lower in neurons from cKO mice compared with those from WT mice (Fig. 6C). We further examined whether $C c 2 d 1 a$ deletion may affect NMDARmediated synaptic transmission at Schaffer collateral-CA1 synapses. As shown in Figure 6D, stimulus-response curves of NMDAR-mediated EPSCs were similar in neurons from WT and $\mathrm{cKO}$ mice (group $\times$ stimulus intensity: $F_{(5,94)}=0.12, p=$ 0.98; WT: $n=8$ neurons from 4 mice; cKO: $n=10$ neurons from 5 mice; two-way repeated-measures ANOVA). EPSCs were completely blocked by D-AP ( $50 \mu \mathrm{M}$, Tocris Bioscience), confirming that they were mediated through activation of NMDARs.

\section{Conditional deletion of $C c 2 d 1 a$ reduces the dendritic complexity of CA1 pyramidal neurons}

To investigate whether $C c 2 d 1 a$ deletion may influence dendritic geometry and spine density, we used Golgi-Cox staining to visualize individual CA1 pyramidal neurons in WT and cKO mice (Fig. 7A), and analyzed the complexity of their dendritic trees. Sholl analysis of reconstructed CA1 pyramidal neurons revealed that $C c 2 d 1 a$ deletion significantly decreased the complexity of both apical $\left(F_{(24,1200)}=1.61, p=0.03\right.$; WT: $n=22$ neurons from 4 mice; cKO: $n=28$ neurons from 4 mice; two-way ANOVA; Fig. $7 B)$ and basal dendrite branching $\left(F_{(19,960)}=2.82, p<0.001\right.$; WT: $n=22$ neurons from 4 mice; cKO: $n=28$ neurons from 4 mice; two-way ANOVA; Fig. 7C) compared with those of WT mice. No significant change in the density of dendritic spine was detected on secondary and tertiary branches of apical dendrites of CA1 pyramidal neurons in cKO mice compared with WT mice $\left(t_{(8)}=0.34, p=0.73\right.$; WT: $n=58$ neurons from 5 mice; $c K O: n=$ 42 neurons from 5 mice; two-tailed unpaired Student's $t$ test; Fig. $7 D, E)$. Additional analysis revealed no significant alteration in
B

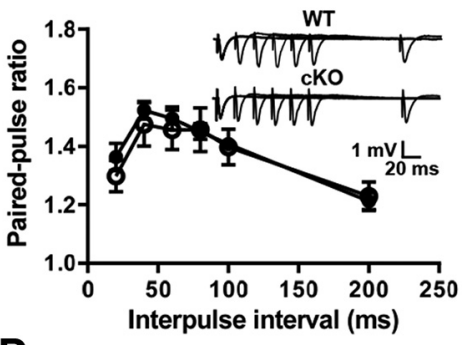

D

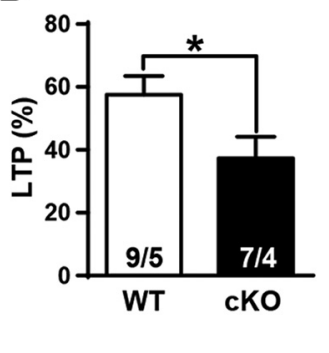
2030
Time (min) 

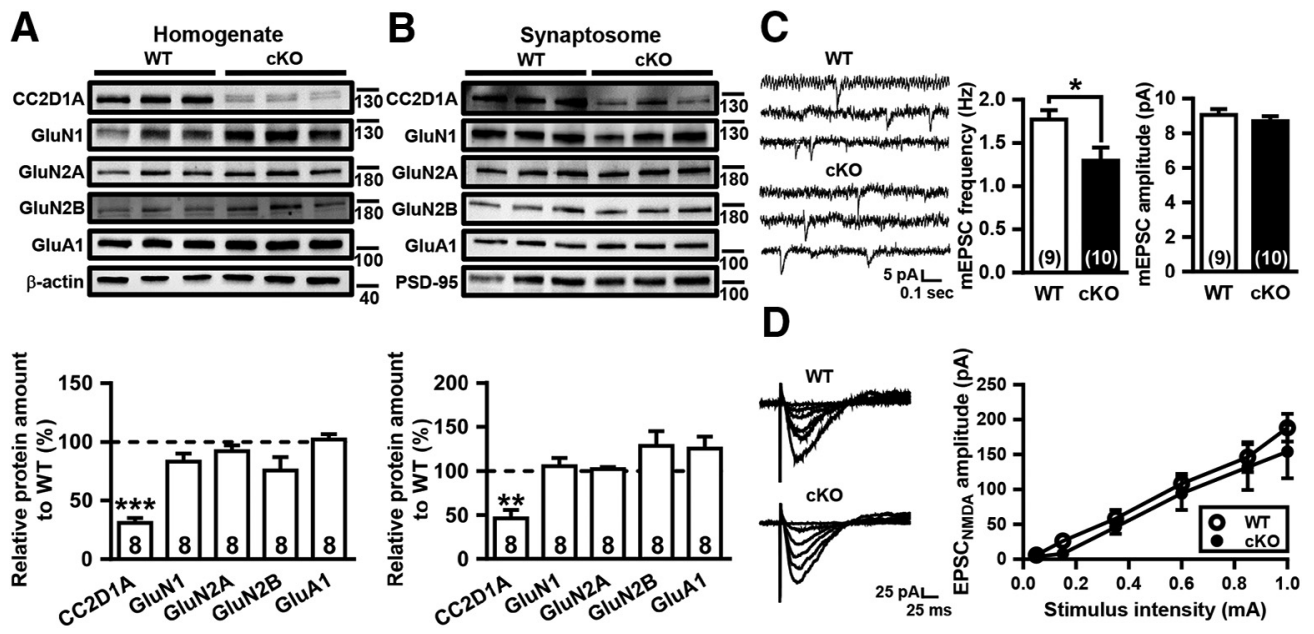

Figure 6. Effects of C 2 d1 1 a deletion on expression of AMPAR and NMDAR subunits, mEPSCS, and evoked NMDAR-mediated EPSCs in the hippocampal CA1 region. $A$, Representative immunoblotting and summary bar graph depicting levels of CC2D1A, GluN1, GluN2A, GluN2B, and GluA1 in hippocampal CA1 tissue homogenates from WT and cK0 mice at 10 weeks of age. Relative expression levels normalized to $\beta$-actin are shown. B, Representative immunoblotting and summary bar graph depicting levels of CC2D1A, GluN1, GluN2A, GluN2B, and GluA1 in crude hippocampal CA1 synaptosomes (P2) prepared from WT and CK0 mice at 10 weeks of age. Relative expression levels normalized to PSD-95 are shown. C, Left, Representative traces showing the mEPSCs of hippocampal CA1 neurons in slices from WT and cKO mice. Summary bar graphs showing comparisons between WT and cKO mice in the averaged frequency (middle) and amplitude (right) of mEPSCS. D, Representative traces and summary data comparing the input- output relationship of NMDAR-mediated EPSCS $\left(\right.$ EPSC $\left._{\text {NMDA }}\right)$ in hippocampal CA1 pyramidal neurons from WT and cKO mice. Data are mean \pm SEM. The total number of animals examined is indicated by $n$ in parentheses. ${ }^{*} p<0.05$, compared with WT group (two-tailed unpaired Student's $t$ test). ${ }^{* *} p<0.01$, compared with WT group (two-tailed unpaired Student's $t$ test). ${ }^{* *} p<0.001$, compared with WT group (two-tailed unpaired Student's $t$ test).

A

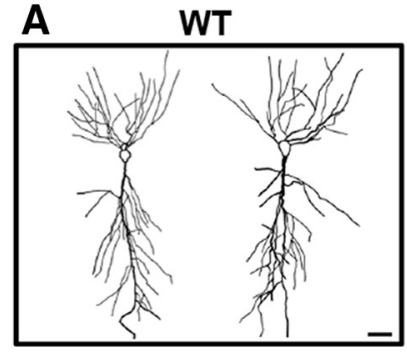

D

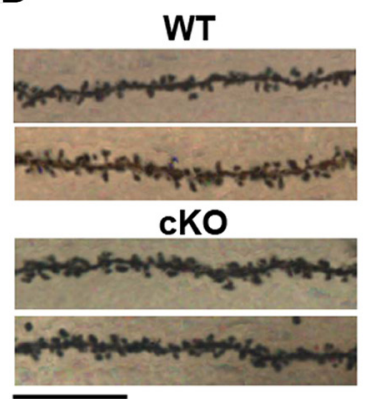

$10 \mu \mathrm{m}$
cKO

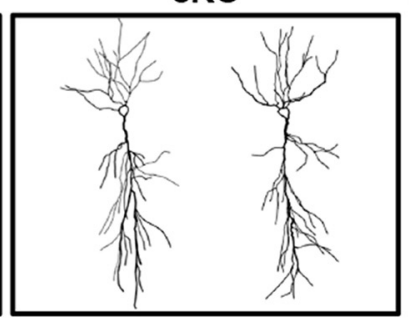

E

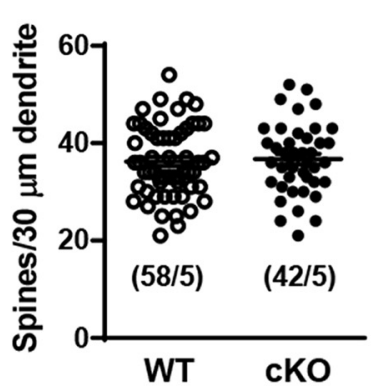

B

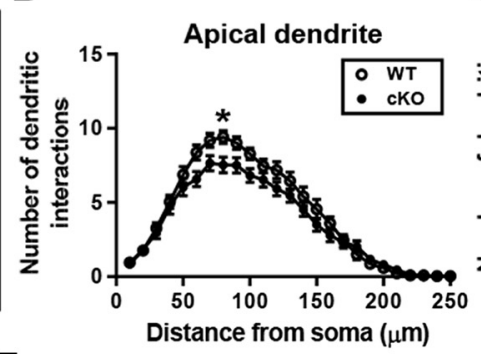

F Mushroom Filopodia Thin Stubby

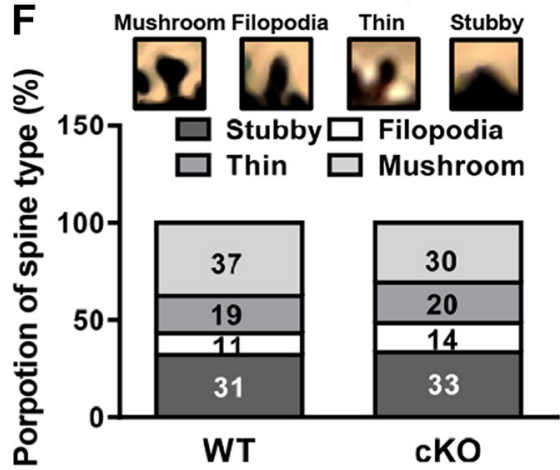

C

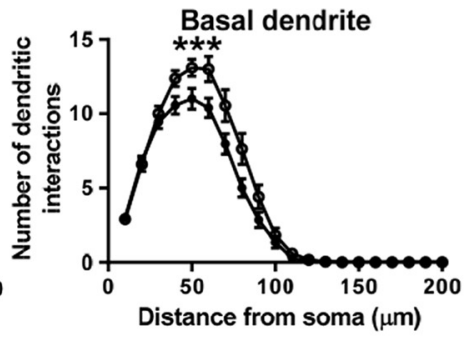

Figure 7. Effects of (C2d1a deletion on dendritic morphology and spine density of hippocampal CA1 pyramidal neurons. $A$, Representative camera lucida tracings of hippocampal CA1 pyramidal neurons from WT and cKO mice. Scale bar, $25 \mu \mathrm{m}$. B, C, Sholl analysis of apical (B) and basal ( $\boldsymbol{C}$ ) dendrites of CA1 pyramidal neurons from WT (22 neurons from 4 mice) and cKO mice (28 neurons from 4 mice). $\boldsymbol{D}$, Representative images of the secondary branch of apical dendrites of CA1 pyramidal neurons from WT and cK0 mice. $\boldsymbol{E}$, Summary scatter plot graphs depicting the density of protrusions in apical dendrites of CA1 pyramidal cells from WT ( 58 neurons from 5 mice) and KKO mice (42 neurons from 5 mice). $\boldsymbol{F}$, Representative images of labeled spines for analysis. Mushroom, filopodia, thin, and stubby spines are identified based on structural measures. C(2d1a deletion does not alter the proportion of dendritic spine types of CA1 pyramidal neurons. Data are mean \pm SEM. Numbers in parentheses indicate neurons/animals examined. ${ }^{*} p<0.05$, compared with WT group (two-Way ANOVA). ${ }^{* * *} p<0.001$, compared with WT group (two-way ANOVA).

phospho-PAK1-3 $\left(t_{(10)}=2.27, p=0.04 ; n=6\right.$ in each group; two-tailed unpaired Student's $t$ test $)$ and phospho-cofilin $\left(t_{(10)}=\right.$ $3.03, p=0.01 ; n=6$ in each group; two-tailed unpaired Student's $t$ test) in hippocampal CA1 tissue homogenates in cKO mice compared with WT mice, whereas the total expression levels of PAK1 and cofilin were unchanged in cKO mice compared with
WT mice (Fig. $8 C$ ), indicating that $C c 2 d 1 a$ deletion results in hyperactive Rac1-PAK-cofilin signaling pathway.

ArhGAP15 is a Rac-specific GTPase-activating protein that negatively regulates Racl activity (Seoh et al., 2003). We then investigated whether $C c 2 d 1 a$ deletion promotes the activation of Racl through a downregulation of ArhGAP15 expression. We 
did not observe significant difference between WT and cKO mice in the expression levels of ArhGAP15 in hippocampal CA1 tissue homogenates $\left(t_{(10)}=0.02, p=\right.$ $0.98 ; n=6$ in each group; two-tailed unpaired Student's $t$ test; Fig. 9A).

Since previous studies have reported that Racl can be conjugated to SUMO protein and this Racl SUMOylation is crucial to maintain the active Rac1-GTP form and enhance Racl activity (CastilloLluva et al., 2010; Yue et al., 2017), we therefore investigated whether $C c 2 d 1 a$ deletion activates Rac1 through increasing Rac1 SUMOylation levels. The Rac1 SUMOylation levels were determined by Rac1 pull-down followed by Western blot analysis using an anti-SUMO2/3 antibody. Remarkably, we found a significant increase in the SUMOylation of Rac1 in cKO mice compared with WT mice (Fig. 9B).

SUMOylation is a highly dynamic process that can be reversed by SENPs (Mukhopadhyay and Dasso, 2007; Gareau and Lima, 2010; Hay, 2013). Previous studies have shown that SENP1 can interact with Rac1 and de- SUMOylate Rac1 to downregulate its activity in cells (Castillo-Lluva et al., 2010; Yue et al., 2017). We therefore examined whether $C c 2 d 1 a$ deletion increases basal Rac1 SUMOylation levels by decreasing expression of SENPs. We found a significant reduction in SENP1 and SENP3 protein levels in cKO mice compared with WT mice (SENP1: $t_{(9)}=$ 2.32, $p=0.04$; WT: $n=6$; cKO: $n=5$; SENP3: $t_{(9)}=3.22, p=0.01$; WT: $n=6$; cKO: $n=5$; two-tailed unpaired Student's $t$ test; Figure $9 C)$. In addition, significant reductions in Senp1 and Senp3 mRNA lev-

els were also observed in cKO mice compared with WT mice $\left(\right.$ Senp $1: t_{(11)}=2.87, p=0.02 ; \mathrm{WT}: n=6 ; \mathrm{cKO}: n=7$; Senp3: $t_{(10)}$ 2.52, $p=0.03$; WT: $n=6$; cKO: $n=6$; two-tailed unpaired Student's $t$ test; Figure 9D). These results suggest that Cc2d1a deletion increases Rac1 SUMOylation and activity, at least in part, through downregulation of SENP1 and SENP3 expression.

Pharmacological inhibition of Racl rescues the impaired LTP and long-term OLM performance in cKO mice

If $C c 2 d 1 a$ deletion-induced increase in basal Racl activity indeed leads to impaired LTP and long-term OLM performance, then Racl blockade ought to rescue these deficits in cKO mice. To manipulate basal Racl activity, we used a Racl inhibitor NSC23766, a small molecule that can inhibit Rac1 activity by interfering with certain Racl guanine nucleotide exchange factors, thus impairing GDP/GTP exchange (Gao et al., 2004). To identify the most appropriate inhibitor concentration to manipulate Racl activity, we performed a set of experiments to determine basal Rac1 activity in the CA1 region of hippocampal slices from WT and cKO mice in the presence of different concentrations of NSC23766. Western blot analysis revealed a significant reduction in Rac1-GTP protein levels $(\sim 50 \%)$ by
NSC23766 $(10 \mu \mathrm{M})$ in cKO mice, whereas Racl activation was almost completely blocked is slices treated with $20 \mu \mathrm{M}$ NSC23766 (Fig. 10A). Because previous studies showed that activation of Racl is associated with the induction of LTP (Haditsch et al., 2009; Martinez and Tejada-Simon, 2011), to avoid complete blockade of Rac1 activity, we used NSC23766 (10 $\mu \mathrm{M})$ to rescue LTP deficit in cKO mice. Remarkably, bath application of NSC23766 prevented the abnormal LTP decay in slices from cKO mice ( $p=0.87 ; n=7$ slices from 5 mice in each group; MannWhitney $U$ test; Fig. $10 B, C$ ) and had no significant effect on LTP in slices from WT mice ( $p=0.14$ compared with WT in the absence of NSC23766; Mann-Whitney $U$ test).

In final experiments, we determined whether NSC23766 treatment may also rescue long-term OLM performance deficit observed in cKO mice. We found that NSC23766 treatment (2.5 $\mu \mathrm{g} / \mu \mathrm{l}$, bilateral intrahippocampal injection) significantly rescued long-term OLM performance in cKO mice. Two-way ANOVA revealed effects of $\mathrm{cKO}\left(F_{(1,26)}=18.04, p=0.0002\right)$, NSC23766 treatment $\left(F_{(1,26)}=12.76, p=0.0014\right)$ and $\mathrm{cKO} \times$ NSC23766 treatment interaction $\left(F_{(1,26)}=10.10, p=0.0038\right.$; $n=7-9$ mice in each group) on the discrimination index (Fig. $10 D)$. Post hoc analysis showed that $\mathrm{CKO}$-vehicle mice had a lower 


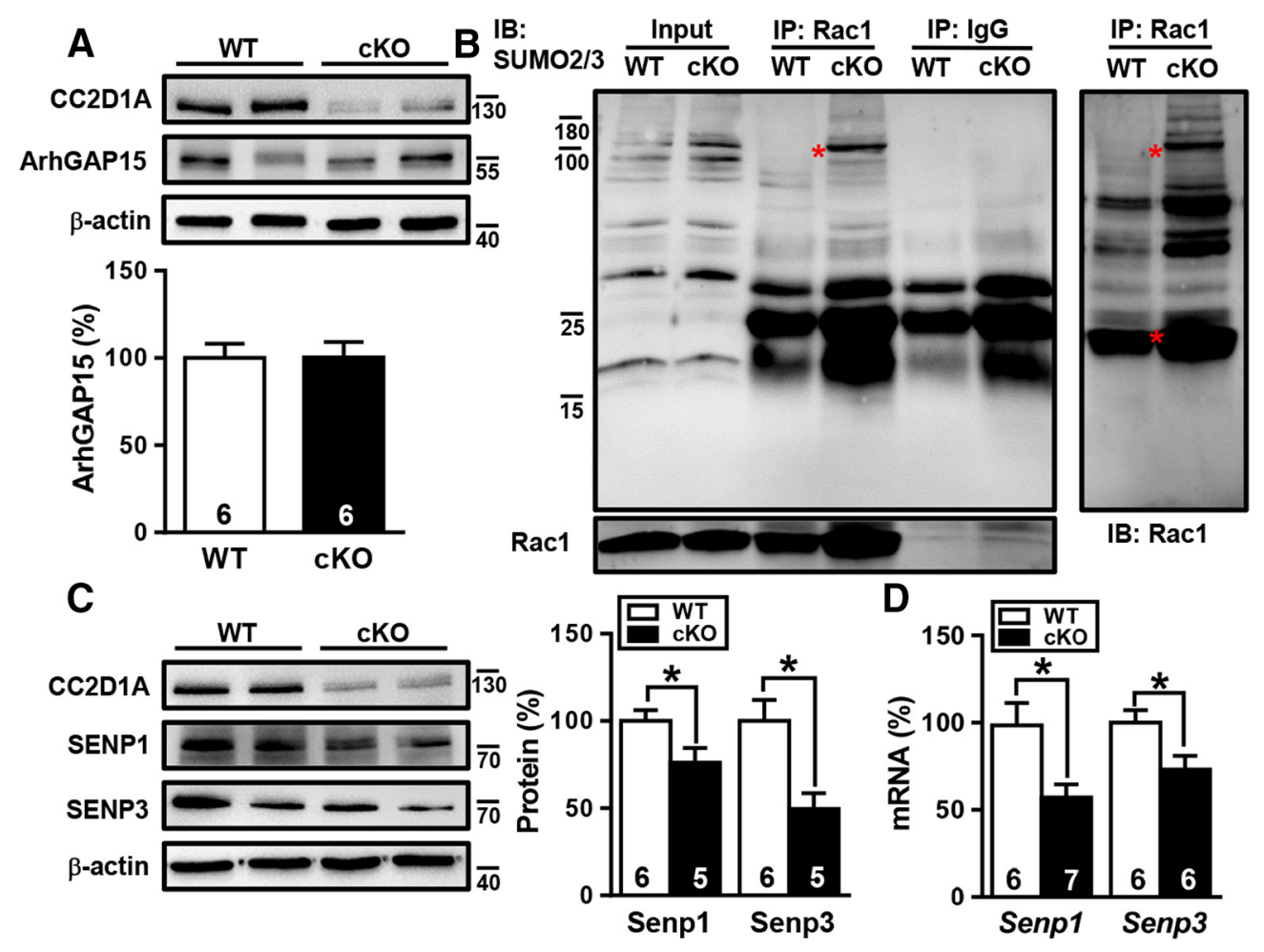

Figure 9. C(2d1a deletion increases Rac1 SUMOylation and activity through downregulation of SENP1 and SENP3 expression. $A$, Representative immunoblotting and corresponding densitometric analysis showing the levels of ArhGAP15 in hippocampal CA1 tissue homogenates from WT and cK0 mice at 10 weeks of age. $\boldsymbol{B}$, Representative immunoblotting showing immunoprecipitation of endogenous Rac1 from hippocampal CA1 tissue homogenates from WT and CK0 mice (Input; Rac1, immunoprecipitation using an antibody against Rac1; lgG, IgG negative control). Left, Immunoblotting using an antibody raised against SUM02/3. Right, Bottom, Immunoblotting using an antibody raised against Rac1 (red asterisk). C, Representative immunoblotting and summary bar graph showing the expression of SENP1 and SENP3 in hippocampal CA1 tissue homogenates from WT and cK0 mice. D, Summary bar graph showing the expression of Senp1 and Senp3 mRNA in the hippocampal CA1 region of WT and cKO mice. Data are mean \pm SEM. The total number of animals examined is indicated by $n$ in parentheses. ${ }^{*} p<0.05$, compared with WT group (two-tailed unpaired Student's $t$ test).

discrimination index than WT-vehicle mice $(p<0.01)$ and cKONSC23766 mice had a higher discrimination index than cKOvehicle mice $(p<0.001)$. In addition, NSC23766 treatment caused no significant changes in total exploration time of both WT and cKO mice. Two-way ANOVA revealed no significant effects of $\mathrm{cKO}\left(F_{(1,26)}=0.64, p=0.43\right)$, NSC23766 treatment $\left(F_{(1,26)}=0.87, p=0.36\right)$, and $\mathrm{cKO} \times$ NSC23766 treatment interaction $\left(F_{(1,26)}=1.68, p=0.20 ; n=7-9\right.$ mice in each group; Fig. 10E).

After we established that pharmacological blockade of Racl hyperactivity can effectively rescue both the synaptic and cognitive deficits observed in cKO mice, we then tested whether NSC23766 improved LTP and long-term OLM performance in cKO mice by restoring the dendritic complexity of CA1 pyramidal neurons. We found that cKO mice treated with NSC23766 still displayed a reduction of dendritic complexity in hippocampal CA1 neurons (Fig. 11A). Sholl analysis of reconstructed CA1 pyramidal neurons revealed no significant differences between cKO-vehicle and cKO-NSC23766 in the complexity of both api$\operatorname{cal}\left(F_{(24,1075)}=0.56, p=0.96\right.$; cKO-vehicle: $n=21$ neurons from 4 mice; cKO-NSC23766: $n=24$ neurons from 4 mice; two-way ANOVA; Fig. $11 B)$ and basal dendrite branching $\left(F_{(19,860)}=0.90\right.$, $p=0.58$; cKO-vehicle: $n=21$ neurons from 4 mice; cKONSC23766: $n=24$ neurons from 4 mice; two-way ANOVA; Fig. $11 C)$.

\section{Discussion}

Using a conditional gene $\mathrm{KO}$ approach, our study identifies the novel involvement of CC2D1A in the regulation of synaptic plas- ticity and cognitive function. We have demonstrated that $C c 2 d 1 a$ cKO mice exhibit a reduction in the maintenance of LTP at Schaffer collateral-CA1 synapses and an impaired long-term OLM performance. Moreover, we provide the first mechanistic evidence that $C c 2 d 1 a$ deletion can increase Rac1 SUMOylation and activity through downregulating SENP1 and SENP3 expression. In particular, we found that suppressing the elevated Racl activity by the Racl inhibitor can effectively rescue both synaptic and cognitive deficits observed in $C c 2 d 1 a$ cKO mice.

Because constitutive $C c 2 d 1 a \mathrm{KO}$ mice died shortly after birth because of their inability to breathe (Zhao et al., 2011; Oaks et al., 2017), cKO mice provide an avenue for elucidating the functional role of CC2D1A in the brain. An earlier study using another forebrain-restricted $C c 2 d 1 a \mathrm{KO}$ mouse model with CamkII $\alpha$-Cre line has shown that $C c 2 d 1 a$ deletion leads to impaired conversion of a transient early-phase LTP to a sustained late-phase LTP in the hippocampal CA1 region (Oaks et al., 2017). Consistent with this finding, we observed that $C c 2 d 1 a$ deletion from hippocampal CA1 excitatory neurons impairs the maintenance of LTP at Schaffer collateral-CA1 synapses, whereas evoked synaptic transmission and presynaptic glutamate release are not altered by $C c 2 d 1 a$ deletion. We were surprised to find that $C c 2 d 1 a$ deletion causes a decrease in the mEPSC frequency but not evoked synaptic responses. Although the reason for the differential regulation of spontaneous and evoked release in response to $C c 2 d 1 a$ deletion remains unclear, one possibility is that spontaneous and evoked release may use distinct molecular mechanisms (Ramirez and Kavalali, 2011), which might be regulated differently by $C c 2 d 1 a$ 
deletion. In addition, our result indicates that LTP deficit in cKO mice is not associated with changes in the expression or subunit composition of postsynaptic glutamate receptors. Given our findings that NSC23766 treatment rescued LTP deficit in slices from cKO mice, it is reasonable to assume that elevated Racl activity may contribute to impaired LTP maintenance in hippocampal CA1 neurons of $C c 2 d 1 a$ cKO mice. This is consistent with previous observations that mice with constitutively active Racl showed an accelerated theta burst stimulation-induced LTP decay in the hippocampal CA1 region (Liu et al., 2016). Furthermore, mice lacking $B C R$ or $A B R$ genes, which encode RaclGTPase-GAP, enhanced Racl activity and exhibited a marked impairment of the maintenance, but not induction of LTP by theta burst stimulation at Schaffer collateral-CA1 synapses (Oh et al., 2010). The precise mechanism by which elevated Rac1 activity negatively regulates LTP maintenance remains to be determined. Given that gene targeting or pharmacologic blockade of Racl also impairs the induction of LTP (Haditsch et al., 2009; Martinez and Tejada-Simon, 2011), it appears likely that elevated Rac1 activity in cKO mice could partially saturate signaling mechanisms responsible for LTP maintenance. An alternative possibility is that Rac1 hyperactivity may evoke compensatory mechanisms to maintain homeostasis under basal condition. This, in turn, would ultimately lead to disruption of Racl activity required for LTP maintenance (Oh et al., 2010). Possible compensatory mechanisms may include enhanced Rac1-GAP activity or reduced activity of Rac1-specific guanine nucleotide exchange factors. Two previous studies have demonstrated the importance of Rac1 signaling for transducing NMDAR activation to cell development (Tolias et al., 2005; Xiao et al., 2013). Hence, Racl hyperactivity may impair LTP by targeting NMDAR function. Because the magnitudes of NMDAR-mediated EPSCs were not altered by $C c 2 d 1 a$ deletion, it is therefore unlikely that excessive Rac1 activity directly inhibits NMDAR function to suppress LTP maintenance. However, this does not exclude the possibility that Racl may act on NMDAR-related downstream signaling to alter LTP.

In addition to its role in regulating synaptic plasticity, our analysis of neuronal morphology also reveals significant reductions in both apical and basal dendritic complexity of CA1 pyramidal neurons in cKO mice. These findings are consistent with previous studies showing that $C c 2 d 1 a$ knockdown reduced dendritic complexity in primary cultures of hippocampal neurons (Al-Tawashi et al., 2012; Manzini et al., 2014). Furthermore, early knockdown of Cc2d1a by in utero electroporation of short hairpin RNA at embryonic day 15.5 was reported to reduce dendritic complexity of cortical neurons at postnatal day 11 (Manzini et al., 2014). However, Oaks et al. (2017) found no significant differences between WT and Cc2d1a KO mice in dendritic complexity of cortical layer $\mathrm{V}$ pyramidal neurons in the somatosensory cortex. Such apparent discrepancies in effects of $C c 2 d 1 a$ deletion
B
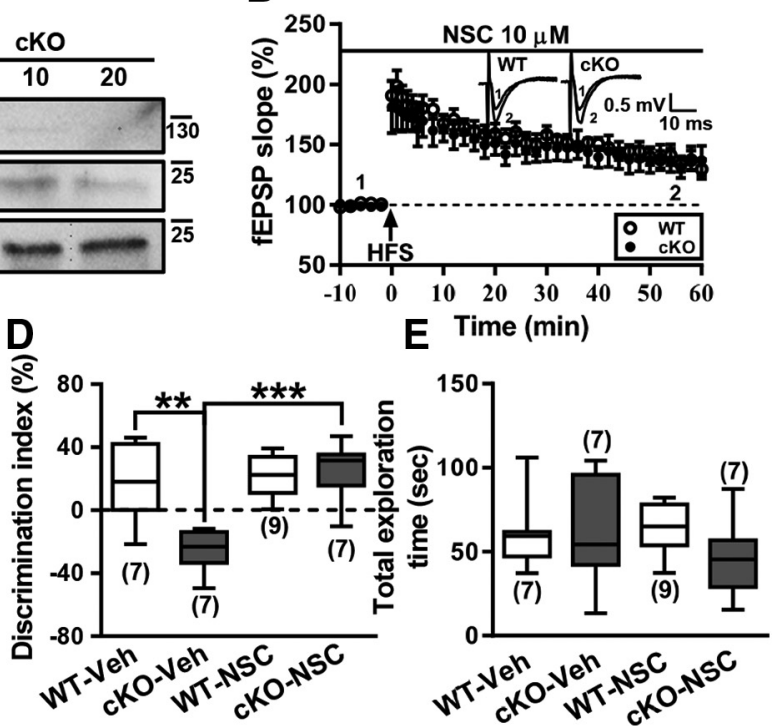

Figure 10. NSC23766 rescues LTP and OLM deficits in CKO mice. $A$, Representative immunoblotting analysis showing the levels

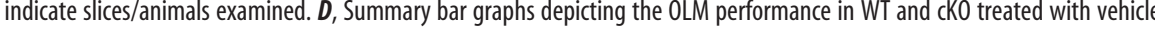
Bonferroni's post hoc analyses). ${ }^{* * *} p<0.001$, compared with WT-Veh or cKO-Veh group (two-way ANOVA followed by Bonfer-
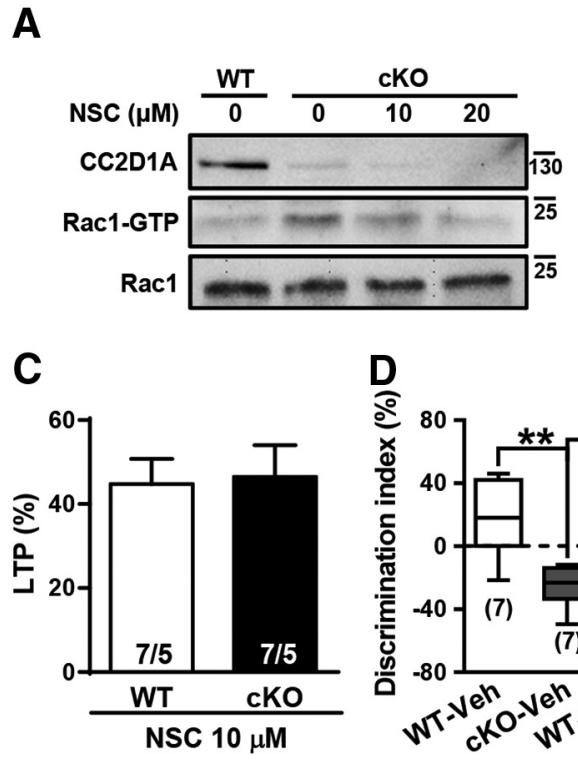
may reflect differences in either brain region- or cell type-specific role of CC2D1A in regulating neuronal morphology. Nonetheless, we did not observe significant changes in dendritic spine density and proportions of spine types in hippocampal CA1 neurons in cKO mice. Similar results were observed by others using different Cc2d1a KO mice (Oaks et al., 2017). Multiple intracellular mechanisms are involved in the control of neuronal morphology (Urbanska et al., 2008; Arikkath, 2012). Further studies are required to elucidate the mechanisms by which CC2D1A regulates neuronal morphology. Recent evidence suggests that Cc2d1a knockdown leads to reduced dendritic complexity by increasing NF- $\kappa \mathrm{B}$ activity because pharmacological inhibition of NF- $\kappa \mathrm{B}$ activity can restore dendritic complexity following Cc2d1a knockdown (Manzini et al., 2014). Another possibility is that $C c 2 d 1 a$ deletion may act by heightening Racl activity and subsequently interfering signaling mechanisms that control neuronal morphology. Indeed, although many studies have demonstrated the importance of Racl in promoting neurite outgrowth (Li et al., 2002; Ng et al., 2002; Lee et al., 2003), it has also been shown that both inhibition and overactivation of Racl can reduce neurite formation (Woo and Gomez, 2006). It is noteworthy that CC2D1A is abundantly expressed in both excitatory and inhibitory interneurons in the CA1 region of the mouse hippocampus. Recent studies have provided evidence that hyperactive Racl can affect the architecture and function of cortical and hippocampal inhibitory interneurons (Zamboni et al., 2016, 2018). The functional role of CC2D1A in inhibitory interneurons remains to be determined.

According to the long-held theory that long-term memory storage relies on LTP (Mayford et al., 2012; Takeuchi et al., 2013), our results demonstrate a strong correlation between hippocampal CA1 LTP and long-term OLM. Our observations that Cc2d1a deletion impairs the maintenance of LTP at Schaffer collateralCA1 synapses, and the persistence of long-term OLM echoes the current concept that CA1 is crucial for hippocampus-dependent OLM formation (Manns and Eichenbaum, 2009; Haettig et al., 2013; Stackman et al., 2016). The fact that microinfusion of NSC23766 into the dorsal hippocampus effectively rescued impaired OLM performance in CKO mice suggests that excessive Racl activity may contribute to cognitive impairment observed after Cc2dla deletion. This assertion is supported by a recent study showing that elevated Racl activity in forebrain regions, including CA1 and DG in the hippocampus, accelerated memory decay in the novel object recognition test (Liu et al., 2016). Two recent studies have further shown that forebrain-specific Cc2d1a cKO mice display reduced memory retention in the novel object recognition and delayed learning in remembering the location of the platform once it was learned in the Morris water maze (Oaks et al., 2017; Zamarbide et al., 2018). In addition to cognitive deficits, we provide further evidence that $\mathrm{cKO}$ mice display altered anxiety-like behavior, as evidenced by measuring performance in the OF, EPM, and LDB tests, confirming that CC2D1A is critically involved in regulating anxious behavioral characteristics (Oaks et al., 2017; Zamarbide et al., 2018).

We have identified Racl as an unidentified and important mediator for Cc2d1a knockdown to impair synaptic plasticity and cognitive function. At the molecular level, we showed that Cc2d1a deletion drastically downregulated SENP1 and SENP3 mRNA and protein expression and consequently repressed SENP-mediated de-SUMOylation of Rac1 to activate Rac1. This SENP-mediated de-SUMOylation of Racl has also been demonstrated in human cancer cells, where the de-SUMOylation activity of SENP1 is crucial for the promoting effect of mutant p53 on
Racl activity to regulate tumor progression (Castillo-Lluva et al., 2010; Yue et al., 2017). Moreover, we observed that SUMO2/3, but not SUMO1 (data not shown), conjugation levels are increased in hippocampal CA1 tissue lysates of cKO mice. Our data are in agreement with evidence showing that SENPs display SUMO paralog specificity and SUMO2/3 deconjugation is more closely related to SENP1 and SENP3 (Mukhopadhyay and Dasso, 2007). Although we still do not know how SUMO maintains Rac1 in activated GTP-bound form, SUMOylational conjugation may affect protein function through either structural changes or altering protein-protein interactions. There is growing evidence indicating that normal regulation of SUMO can become disrupted under neuropathological conditions and further contribute to disease pathogenesis (Sarge and Park-Sarge, 2009; Lee et al., 2014).

In conclusion, our results demonstrate that $C c 2 d 1 a$ deletion activates Rac1 through downregulation of SENPs to inhibit SENP-mediated Rac1 de-SUMOlation, which in turn impairs the maintenance of hippocampal CA1 LTP and long-term OLM performance. Results from this study uncover an unidentified and important mechanism underlying the functional relevance of CC2D1A in the brain and reveal a novel mechanism for Rac1 hyperactivation in synaptic plasticity and cognitive function. Our results also reveal that targeting Racl and its downstream signaling may be a potential therapeutic strategy for treating cognitive deficits caused by $C c 2 d 1 a$ mutations.

\section{References}

Al-Tawashi A, Gehring C (2013) Phosphodiesterase activity is regulated by CC2D1A that is implicated in non-syndromic intellectual disability. Cell Commun Signal 11:47.

Al-Tawashi A, Jung SY, Liu D, Su B, Qin J (2012) Protein implicated in nonsyndromic mental retardation regulates protein kinase A activity. J Biol Chem 287:14644-14658.

Arikkath J (2012) Molecular mechanisms of dendrite morphogenesis. Front Cell Neurosci 6:61.

Basel-Vanagaite L, Attia R, Yahav M, Ferland RJ, Anteki L, Walsh CA, Olender T, Straussberg R, Magal N, Taub E, Drasinover V, Alkelai A, Bercovich D, Rechavi G, Simon AJ, Shohat M (2006) The CC2D1A, a member of a new gene family with $\mathrm{C} 2$ domains, is involved in autosomal recessive non-syndromic mental retardation. J Med Genet 43:203-210.

Bourin M, Hascoët M (2003) The mouse light/dark box test. Eur J Pharmacol 463:55-65.

Castillo-Lluva S, Tatham MH, Jones RC, Jaffray EG, Edmondson RD, Hay RT, Malliri A (2010) SUMOylation of the GTPase Racl is required for optimal cell migration. Nat Cell Biol 12:1078-1085.

Chang CH, Lai LC, Cheng HC, Chen KR, Syue YZ, Lu HC, Lin WY, Chen SH, Huang HS, Shiau AL, Lei HY, Qin J, Ling P (2011) TBK1-associated protein in endolysosomes (TAPE) is an innate immune regulator modulating the TLR3 and TLR4 signaling pathways. J Biol Chem 286:70437051 .

Chen KR, Chang CH, Huang CY, Lin CY, Lin WY, Lo YC, Yang CY, Hsing EW, Chen LF, Shih SR, Shiau AL, Lei HY, Tan TH, Ling P (2012) TBK1associated protein in endolysosomes (TAPE)/CC2D1A is a key regulator linking RIG-I-like receptors to antiviral immunity. J Biol Chem 287: 32216-32221.

Chou D, Huang CC, Hsu KS (2014) Brain-derived neurotrophic factor in the amygdala mediates susceptibility to fear conditioning. Exp Neurol 255:19-29.

Franklin K, Paxinos G (2008) The mouse brain in stereotaxic coordinates. San Diego: Elsevier Academic.

Freischmidt A, Wieland T, Richter B, Ruf W, Schaeffer V, Müller K, Marroquin N, Nordin F, Hübers A, Weydt P, Pinto S, Press R, Millecamps S, Molko N, Bernard E, Desnuelle C, Soriani MH, Dorst J, Graf E, Nordström U, et al. (2015) Haploinsufficiency of TBK1 causes familial ALS and fronto-temporal dementia. Nat Neurosci 18:631-636.

Gao Y, Dickerson JB, Guo F, Zheng J, Zheng Y (2004) Rational design and characterization of a rac GTPase-specific small molecule inhibitor. Proc Natl Acad Sci U S A 101:7618-7623. 
Gareau JR, Lima CD (2010) The SUMO pathway: emerging mechanisms that shape specificity, conjugation and recognition. Nat Rev Mol Cell Biol 11:861-871.

Gualdoni S, Albertinazzi C, Corbetta S, Valtorta F, de Curtis I (2007) Normal levels of Racl are important for dendritic but not axonal development in hippocampal neurons. Biol Cell 99:455-464.

Haditsch U, Leone DP, Farinelli M, Chrostek-Grashoff A, Brakebusch C, Mansuy IM, McConnell SK, Palmer TD (2009) A central role for the small GTPase Rac1 in hippocampal plasticity and spatial learning and memory. Mol Cell Neurosci 41:409-419.

Haettig J, Stefanko DP, Multani ML, Figueroa DX, McQuown SC, Wood MA (2011) HDAC inhibition modulates hippocampus-dependent longterm memory for object location in a CBP-dependent manner. Learn Mem 18:71-79.

Haettig J, Sun Y, Wood MA, Xu X (2013) Cell-type specific inactivation of hippocampal CA1 disrupts location-dependent object recognition in the mouse. Learn Mem 20:139-146.

Hay RT (2013) Decoding the SUMO signal. Biochem Soc Trans 41:463-473.

Huang CC, Hsu KS (2006) Sustained activation of metabotropic glutamate receptor 5 and protein tyrosine phosphatases mediate the expression of (S)-3,5-dihydroxyphenylglycine-induced long-term depression in the hippocampal CA1 region. J Neurochem 96:179-194.

Huang CC, Lin YS, Lee CC, Hsu KS (2014) Cell type-specific expression of Eps8 in the mouse hippocampus. BMC Neurosci 15:26.

Huang YF, Yang CH, Huang CC, Tai MH, Hsu KS (2010) Pharmacological and genetic accumulation of hypoxia-inducible factor-1alpha enhances excitatory synaptic transmission in hippocampal neurons through the production of vascular endothelial growth factor. J Neurosci 30:60806093.

Huttner WB, Schiebler W, Greengard P, De Camilli P (1983) Synapsin I (protein I), a nerve terminal-specific phosphoprotein: III. Its association with synaptic vesicles studied in a highly purified synaptic vesicle preparation. J Cell Biol 96:1374-1388.

Lee A, Li W, Xu K, Bogert BA, Su K, Gao FB (2003) Control of dendritic development by the Drosophila fragile X-related gene involves the small GTPase Rac1. Development 130:5543-5552.

Lee CC, Huang CC, Hsu KS (2011) Insulin promotes dendritic spine and synapse formation by the PI3K/Akt/mTOR and Racl signaling pathways. Neuropharmacology 61:867-879.

Lee CC, Huang CC, Hsu KS (2015) The phospholipid-binding protein SESTD1 negatively regulates dendritic spine density by interfering with Rac1-Trio8 signaling pathway. Sci Rep 5:13250.

Lee L, Dale E, Staniszewski A, Zhang H, Saeed F, Sakurai M, Fa' M, Orozco I, Michelassi F, Akpan N, Lehrer H, Arancio O (2014) Regulation of synaptic plasticity and cognition by SUMO in normal physiology and Alzheimer's disease. Sci Rep 4:7190.

Li X, Saint-Cyr-Proulx E, Aktories K, Lamarche-Vane N (2002) Racl and Cdc42 but not RhoA or rho kinase activities are required for neurite outgrowth induced by the netrin-1 receptor DCC (deleted in colorectal cancer) in N1E-115 neuroblastoma cells. J Biol Chem 277:15207-15214.

Lin YT, Chen CC, Huang CC, Nishimori K, Hsu KS (2017) Oxytocin stimulates hippocampal neurogenesis via oxytocin receptor expressed in CA3 pyramidal neurons. Nat Commun 8:537.

Lin YT, Hsieh TY, Tsai TC, Chen CC, Huang CC, Hsu KS (2018) Conditional deletion of hippocampal CA2/CA3a oxytocin receptors impairs the persistence of long-term social recognition memory in mice. J Neurosci 38:1218-1231.

Liu Y, Du S, Lv L, Lei B, Shi W, Tang Y, Wang L, Zhong Y (2016) Hippocampal activation of Racl regulates the forgetting of object recognition memory. Curr Biol 26:2351-2357.

Manns JR, Eichenbaum H (2009) A cognitive map for object memory in the hippocampus. Learn Mem 16:616-624.

Manzini MC, Xiong L, Shaheen R, Tambunan DE, Di Costanzo S, Mitisalis V, Tischfield DJ, Cinquino A, Ghaziuddin M, Christian M, Jiang Q, Laurent S, Nanjiani ZA, Rasheed S, Hill RS, Lizarraga SB, Gleason D, Sabbagh D, Salih MA, Alkuraya FS, et al. (2014) CC2D1A regulates human intellectual and social function as well as NF- $\kappa \mathrm{B}$ signaling homeostasis. Cell Rep 8:647-655.

Martinez LA, Tejada-Simon MV (2011) Pharmacological inactivation of the small GTPase Rac1 impairs long-term plasticity in the mouse hippocampus. Neuropharmacology 61:305-312.
Matsuda A, Suzuki Y, Honda G, Muramatsu S, Matsuzaki O, Nagano Y, Doi T, Shimotohno K, Harada T, Nishida E, Hayashi H, Sugano S (2003) Large-scale identification and characterization of human genes that activate NF-kappaB and MAPK signaling pathways. Oncogene 22:3307-3318.

Mayford M, Siegelbaum SA, Kandel ER (2012) Synapses and memory storage. Cold Spring Harb Perspect Biol 4:a005751.

Mukhopadhyay D, Dasso M (2007) Modification in reverse: the SUMO proteases. Trends Biochem Sci 32:286-295.

Mumby DG, Glenn MJ, Nesbitt C, Kyriazis DA (2002) Dissociation in retrograde memory for object discriminations and object recognition in rats with perirhinal cortex damage. Behav Brain Res 132:215-226.

Nakamura A, Naito M, Tsuruo T, Fujita N (2008) Freud-1/Akil, a novel PDK1-interacting protein, functions as a scaffold to activate the PDK1/ Akt pathway in epidermal growth factor signaling. Mol Cell Biol 28:5996-6009.

Nakamura A, Arai H, Fujita N (2009) Centrosomal Akil and cohesin function in separase-regulated centriole disengagement. J Cell Biol 187:607-614.

Ng J, Nardine T, Harms M, Tzu J, Goldstein A, Sun Y, Dietzl G, Dickson BJ, Luo L (2002) Rac GTPases control axon growth, guidance and branching. Nature 416:442-447.

Oaks AW, Zamarbide M, Tambunan DE, Santini E, Di Costanzo S, Pond HL, Johnson MW, Lin J, Gonzalez DM, Boehler JF, Wu GK, Klann E, Walsh CA, Manzini MC (2017) Cc2d1a loss of function disrupts functional and morphological development in forebrain neurons leading to cognitive and social deficits. Cereb Cortex 27:1670-1685.

Oh D, Han S, Seo J, Lee JR, Choi J, Groffen J, Kim K, Cho YS, Choi HS, Shin H, Woo J, Won H, Park SK, Kim SY, Jo J, Whitcomb DJ, Cho K, Kim H, Bae YC, Heisterkamp N, et al. (2010) Regulation of synaptic Racl activity, long-term potentiation maintenance, and learning and memory by BCR and ABR rac GTPase-activating proteins. J Neurosci 30:1413414144.

Ou XM, Lemonde S, Jafar-Nejad H, Bown CD, Goto A, Rogaeva A, Albert PR (2003) Freud-1: a neuronal calcium-regulated repressor of the 5-HT1A receptor gene. J Neurosci 23:7415-7425.

Pellow S, Chopin P, File SE, Briley M (1985) Validation of open:closed arm entries in an elevated plus-maze as a measure of anxiety in the rat. J Neurosci Methods 14:149-167.

Pyronneau A, He Q, Hwang JY, Porch M, Contractor A, Zukin RS (2017) Aberrant Rac1-cofilin signaling mediates defects in dendritic spines, synaptic function, and sensory perception in fragile X syndrome. Sci Signal 10:eaan0852.

Ramirez DM, Kavalali ET (2011) Differential regulation of spontaneous and evoked neurotransmitter release at central synapses. Curr Opin Neurobiol 21:275-282.

Rogaeva A, Ou XM, Jafar-Nejad H, Lemonde S, Albert PR (2007) Differential repression by freud-1/CC2D1A at a polymorphic site in the dopamine- $\mathrm{D}_{2}$ receptor gene. J Biol Chem 282:20897-20905.

Sananbenesi F, Fischer A, Wang X, Schrick C, Neve R, Radulovic J, Tsai LH (2007) A hippocampal Cdk5 pathway regulates extinction of contextual fear. Nat Neurosci 10:1012-1019.

Sarge KD, Park-Sarge OK (2009) Sumoylation and human disease pathogenesis. Trends Biochem Sci 34:200-205.

Schulz J, Franke K, Frick M, Schumacher S (2016) Different roles of the small GTPases Rac1, Cdc42, and RhoG in CALEB/NGC-induced dendritic tree complexity. J Neurochem 139:26-39.

Sener EF, Cikili Uytun M, Korkmaz Bayramov K, Zararsiz G, Oztop DB, Canatan H, Ozkul Y (2016) The roles of CC2D1A and HTR1A gene expressions in autism spectrum disorders. Metab Brain Dis 31:613-619.

Seoh ML, Ng CH, Yong J, Lim L, Leung T (2003) ArhGAP15, a novel human RacGAP protein with GTPase binding property. FEBS Lett 539:131-137.

Shi ZY, Li YJ, Zhang KJ, Gao XC, Zheng ZJ, Han N, Zhang FC (2012) Positive association of CC2D1A and CC2D2A gene haplotypes with mental retardation in a Han Chinese population. DNA Cell Biol 31:80-87.

Stackman RW Jr, Cohen SJ, Lora JC, Rios LM (2016) Temporary inactivation reveals that the CA1 region of the mouse dorsal hippocampus plays an equivalent role in the retrieval of long-term object memory and spatial memory. Neurobiol Learn Mem 133:118-128.

Szewczyk B, Albert PR, Rogaeva A, Fitzgibbon H, May WL, Rajkowska G, Miguel-Hidalgo JJ, Stockmeier CA, Woolverton WL, Kyle PB, Wang Z, Austin MC (2010) Decreased expression of freud-1/CC2D1A, a tran- 
scriptional repressor of the $5-\mathrm{HT}_{1 \mathrm{~A}}$ receptor, in the prefrontal cortex of subjects with major depression. Int J Neuropsychopharmacol 13: 1089-1101.

Takeuchi T, Duszkiewicz AJ, Morris RG (2013) The synaptic plasticity and memory hypothesis: encoding, storage and persistence. Philos Trans R Soc Lond B Biol Sci 369:20130288.

Tolias KF, Bikoff JB, Burette A, Paradis S, Harrar D, Tavazoie S, Weinberg RJ, Greenberg ME (2005) The Rac1-GEF Tiam1 couples the NMDA receptor to the activity-dependent development of dendritic arbors and spines. Neuron 45:525-538.

Tyler WJ, Pozzo-Miller L (2003) Miniature synaptic transmission and $\mathrm{BDNF}$ modulate dendritic spine growth and form in rat CA1 neurones. J Physiol 553:497-509.

Urbanska M, Blazejczyk M, Jaworski J (2008) Molecular basis of dendritic arborization. Acta Neurobiol Exp 68:264-288.

Wang YT, Huang CC, Lin YS, Huang WF, Yang CY, Lee CC, Yeh CM, Hsu KS (2017) Conditional deletion of Eps8 reduces hippocampal synaptic plasticity and impairs cognitive function. Neuropharmacology 112:113-123.

Woo S, Gomez TM (2006) Racl and RhoA promote neurite outgrowth through formation and stabilization of growth cone point contacts. J Neurosci 26:1418-1428.

Xiao L, Hu C, Yang W, Guo D, Li C, Shen W, Liu X, Aijun H, Dan W, He C (2013) NMDA receptor couples Rac1-GEF Tiam1 to direct oligodendrocyte precursor cell migration. Glia 61:2078-2099.

Yang CH, Huang CC, Hsu KS (2012) A critical role for protein tyrosine phosphatase nonreceptor type 5 in determining individual susceptibility to develop stress-related cognitive and morphological changes. J Neurosci 32:7550-7762.

Yeh CM, Huang CC, Hsu KS (2012) Prenatal stress alters hippocampal syn- aptic plasticity in young rat offspring through preventing the proteolytic conversion of pro-brain-derived neurotrophic factor (BDNF) to mature BDNF. J Physiol 590:991-1010.

Yue X, Zhang C, Zhao Y, Liu J, Lin AW, Tan VM, Drake JM, Liu L, Boateng MN, Li J, Feng Z, Hu W (2017) Gain-of-function mutant p53 activates small GTPase Racl through SUMOylation to promote tumor progression. Genes Dev 31:1641-1654.

Zamarbide M, Oaks AW, Pond HL, Adelman JS, Manzini MC (2018) Loss of the intellectual disability and autism gene Cc2dla and its homolog Cc2d1b differentially affect spatial memory, anxiety, and hyperactivity. Front Genet 9:65.

Zamboni V, Armentano M, Sarò G, Ciraolo E, Ghigo A, Germena G, Umbach A, Valnegri P, Passafaro M, Carabelli V, Gavello D, Bianchi V, D’Adamo P, de Curtis I, El-Assawi N, Mauro A, Priano L, Ferri N, Hirsch E, Merlo GR (2016) Disruption of ArhGAP15 results in hyperactive Rac1, affects the architecture and function of hippocampal inhibitory neurons and causes cognitive deficits. Sci Rep 6:34877.

Zamboni V, Armentano M, Berto G, Ciraolo E, Ghigo A, Garzotto D, Umbach A, DiCunto F, Parmigiani E, Boido M, Vercelli A, El-Assawy N, Mauro A, Priano L, Ponzoni L, Murru L, Passafaro M, Hirsch E, Merlo GR (2018) Hyperactivity of Rac1-GTPase pathway impairs neuritogenesis of cortical neurons by altering actin dynamics. Sci Rep 8:7254.

Zhao M, Li XD, Chen Z (2010) CC2D1A, a DM14 and C2 domain protein, activates NF- $\kappa$ B through the canonical pathway. J Biol Chem 285: 24372-24380.

Zhao M, Raingo J, Chen ZJ, Kavalali ET (2011) Cc2d1a, a C2 domain containing protein linked to nonsyndromic mental retardation, controls functional maturation of central synapses. J Neurophysiol 105:1506-1515. 